\title{
Evaluation of the Critical Plastic Region Length in Slender Reinforced Concrete Bridge Columns
}

\author{
Ata Babazadeh, ${ }^{1}$ Rigoberto Burgueño, ${ }^{2, *}$ and Pedro F. Silva ${ }^{3}$
}

\section{Introduction}

Reinforced concrete ( $\mathrm{RC}$ ) bridge columns are typically designed to endure moderate to strong earthquake events by experiencing significant inelastic deformations [1-3]. These inelastic deformations, which are often associated with damage to the column, concentrate at the end regions where moment demands are maximum [4]. The portion of the column over which inelastic deformations take place is commonly known as the critical plastic region; and a ductile inelastic flexural response is necessary along this region to dissipate the seismic energy. Design guidelines [5-11] require special detailing to ensure such ductile response, by providing adequate confinement steel reinforcement over the plastic region. Also, seismic retrofitting and strengthening strategies typically involve providing additional transverse confinement over the critical plastic region of earthquake-resistant RC columns with inadequate transverse reinforcement. Having an accurate account of the length of the plastic region $\left(L_{p r}\right)$ is thus essential for proper seismic design, retrofitting, and strengthening plans.

The plastic region length $\left(L_{p r}\right)$ should be distinguished from the plastic hinge length $\left(L_{p}\right)$ since the former represents the physical region over which plastic deformations actually spread along the RC member length; whereas, the latter is a fictitious term used in lumped plasticity models to combine all sources of inelastic deformations to determine the column's post-yield displacement

\footnotetext{
${ }^{1}$ Graduate Student Researcher, Dept. of Civil and Env. Eng., Michigan State Univ., East Lansing, MI, 48824-1226

${ }^{2}$ Professor, Dept. of Civil and Env. Eng., Michigan State Univ., East Lansing, MI, 48824-1226

${ }^{3}$ Associate Professor, Dept. of Civil and Env. Eng., The George Washington University, Washington, DC, 20052

* Corresponding Author
} 
$[12,13]$. Yet, the plastic hinge length is related to the length of the plastic region since $L_{p r}$ captures the inelastic deformation contribution to $L_{p}$ that spreads along the member due to flexure, known as the moment gradient component [14-16].

Experimental programs on large-scale test units have been typically used to determine the extent of the plastic region. Based on experimental results, empirical expressions have been proposed to predict the extent of the plastic region $\left(L_{p r}\right)$. Yet, these expressions were derived from the tests mostly conducted on non-slender columns, i.e., with aspect ratios $(L / D)$ less than 6 [17]. The significance of slenderness in contributing to the extent of the plastic region was thus generally disregarded in prior studies and the work herein shows that it was underestimated. This is contrary to the fact that slender columns considerably bend under the applied loads. The excessive member deformation away from the chord-line $(\delta)$ in conjunction with the applied axial load $(P)$ generates additional second-order moment (P- $\delta$ ) that contributes to the extent of the plastic region. The increase in $L_{p r}$ due to member deformation and P- $\delta$ moment is schematically depicted in Fig. 1, in which the nonlinear moment gradient leads to a significantly larger plastic region than the one resulting from a linear moment gradient. It should be noted that the additional moment caused by $\mathrm{P}-\Delta$ effects, which is the product of the axial load $(P)$ and the total displacement of the column at top $(\Delta)$, is included in the linear moment gradient. Therefore, current design guidelines for the length of the critical plastic region need reevaluation for slenderness effects. This is crucial since underestimating $L_{p r}$ for seismic design of RC columns leads to insufficient detailing for a ductile response and adversely affects the reliability of the structure for sustaining significant inelastic deformations before failure.

Research endeavors have also led to proposed expressions for $L_{p r}$ (and moment gradient component of $L_{p}$ ) in RC beams [18-20] and columns [12, 21-23]. However, linear moment 
gradients along the member's height were assumed for developing these $L_{p r}$ (and $L_{p}$ ) expressions. Therefore, the effect of nonlinear moment gradients due to $\mathrm{P}-\delta$ moments is not fully captured in current $L_{p r}$ models. This explains, to the authors' knowledge, the reason that most of the available $L_{p r}$ expressions lack any term to include the effects of slenderness. Therefore, developing an expression for $L_{p r}$ that includes the effect of slenderness and second-order nonlinear moment gradient on the extent of the plastic region is essential for the proper design of slender RC columns.

\section{Background}

\subsection{Current Seismic Design Guidelines}

Seismic design guidelines require special detailing and enhanced confinement steel reinforcement in the plastic regions of RC columns in order to ensure stable ductile response. The ACI code (ACI-318-11) [9] and Eurocode 8 for buildings (EN 1998-1:2004) [6] specify the length of the critical region ( $l_{o}$ and $l_{c r}$ as referred to by $\mathrm{ACI}$ and $\mathrm{EN}-1$, respectively) in columns of ductile moment frames to be the larger of: (a) maximum dimension of the cross section, (b) one-sixth of the clear span, or (c) $450 \mathrm{~mm}$. The length of the special detailing zone $\left(l_{o}\right)$ according to the Canadian standard (CAN/CSA-A23.3-04) [5] for axial load ratios $\left(P / f^{\prime} A_{g}\right)$ less than 0.5 is the greater of: (a) 1.5 times the largest cross-section dimension, or (b) one-sixth of the clear span length. The AASHTO seismic design guidelines [10] define a plastic region length $\left(L_{p r}\right.$ as referred to by AASHTO) in bridge piers as the largest value of: (a) 1.5 times the dimension of the cross section in the bending direction, (b) the length of the region where the moment demand exceeds $75 \%$ of the maximum plastic moment, or (c) the analytical plastic hinge length $\left(L_{p}\right)$. Caltrans [11] mandates a ductile response for the plastic hinge region $\left(L_{p r}\right)$ in a way similar to the AASHTO recommendations with the exception of the last criterion, which is switched by the one-fourth of the distance from the location of maximum moment to the point of contra-flexure. The New 
Zealand standard (NZS 3101) [8] and Eurocode 8 for bridges (EN 1998-2:2005) [7] require the ductile detailing length ( $l_{y}$ and $l_{h}$ as they are respectively referred to by NZS and EN-2) to be the greater of: (a) the dimension of the cross section in the direction of the resisting moment and (b) the length of the region over which the design moment exceeds $80 \%$ of the end moment for $P / f^{\prime}{ }_{c} A_{g}<0.25$, which is often the maximum axial load level in bridge columns. The noted design recommendations for the length of the plastic region are reassessed for slenderness effects in light of the test data reported here.

\subsection{Current $L_{p r}$ Expressions}

Most researchers have dealt with $L_{p r}$ as the moment gradient component for plastic hinge length $\left(L_{p}\right)$ models [21-23]. As a consequence, explicit expressions for $L_{p r}$, similar to the models proposed by Hines et al. [12], and Dowel and Hines [24], are rare in the literature. Although, current $L_{p}$ models have distinct terms for the moment gradient component, the relationship between the moment gradient term and $L_{p r}$ is not well-defined due to uncertainty about the distribution of inelastic curvatures over the plastic region. If a linear distribution for the inelastic curvatures is assumed, which is reasonable for most RC columns [12], a factor of 2 is used to relate the lumpedplasticity models to the extent of the plastic region according to Eq. (1):

$$
L_{p r}=2\left(L_{p}-L_{s p}\right)
$$

where $L_{s p}$ represents the terms of $L_{p}$ model that account for the strain-penetration (or bond-slip) effect. While $L_{p}$ models do not characterize the physical length of the plastic region, it is of importance to reassess the moment gradient components of $L_{p}$ models with respect to experimental results from slender test units. 


\section{Experimental Program}

Experimental data to evaluate the effects of slenderness on $L_{p r}$ was extracted from tests conducted by the authors on three large-scale specimens of slender RC bridge columns. Only pertinent information and results from the tests are provided in this paper. A more detailed account of the test procedures and results can be found in reference [25].

\subsection{Test Units}

The length of the plastic region in slender columns was studied based on the experimental testing of three half-scale RC bridge columns with aspect ratios $(L / D)$ of 10 and 12 . The columns had a circular cross section with a diameter of $610 \mathrm{~mm}$ and were detailed to behave in a ductile manner according to the Caltrans [11] design guide. The test units differed in their longitudinal reinforcement ratio $\left(A_{s} / A_{g}\right)$, aspect ratio and axial load ratio $\left(P / f^{\prime} A_{g}\right)$, respectively ranging from $1.5 \%$ to 3\%, 10 to 12, and 5\% to 10\%. Details of the test units are presented in Table 1, in which the columns' identification names have 6 digits, where the first two digits show $L / D$; the two middle digits represent $\rho_{s l}$ and the last two digits indicate the nominal $P / f^{\prime} A_{g}$. Details of the experiments on columns M123005 and M121505 are reported in reference [25]. Column M101510 was tested in a similar fashion and its results are reported in this paper. Geometry and reinforcement details for the test units are shown in Fig. 2 (a). Material properties for concrete, longitudinal, and transverse reinforcement steel were evaluated using standard testing. The experimental material properties and details of the reinforcement geometry are given in Table $\mathbf{1}$.

\subsection{Test Setup}

The columns were tested as free-standing cantilevers with a footing affixed to the laboratory reaction floor at the base level and free end at the top, as depicted in Fig. 2 (c). The test units thus represented the actual bridge columns between the points of maximum moment demand at the 
base and contra-flexure at the top. Constant axial load levels $(P)$ of 712 and $1334 \mathrm{kN}$, approximately corresponding to $0.05 f^{\prime} A_{g}$ and $0.1 f^{\prime}{ }_{c} A_{g}$, were applied to the columns throughout the test. The axial load setup consisted of two hydraulic jacks and high-strength steel rods reacting against the column's top block through a spandrel beam. The two axial loading rods were anchored to the laboratory floor at their lower end and were post-tensioned. The inclination angle of the axial force $(\theta)$ was thus equal to the rotation angle of the column chord line, $\quad \sin ^{-1}\left(\Delta_{t o p} / L\right)$. For the tests conducted by the authors, $\theta$ was at most 0.07 radians. This implies that the axial component of $P$, which is defined by $P \cos \theta$, can be assumed as $P$ with less than $0.3 \%$ error. Detailed accounts of axial and lateral loading setups can be found in reference [25].

\subsection{Test Procedure}

Tests were conducted quasi-statically with a fully reversed cyclic loading pattern, which can be found in the literature [26]. First, a lateral force, which generates a moment demand equal to the first yield moment $\left(M_{y}^{\prime}\right)$ at the base level, was applied to the test columns. $M_{y}^{\prime}$ is the moment that causes yielding on the extreme longitudinal reinforcing rebar in tension. Values of $M_{y}^{\prime}$ were determined from section moment-curvature analyses prior to the tests. The top displacement at first yield $\left(\Delta_{y}^{\prime}\right)$ was measured and used to calculate the ideal yield displacement, $\Delta_{y}$, according to Priestley et al. [27] using $\Delta_{y}=\Delta_{y}^{\prime} \cdot M_{n} / M_{y}^{\prime}$ where, $M_{n}$ is the moment at which either the extreme confined concrete fiber in compression reached $\varepsilon_{c}=-0.004$ or the extreme steel fiber in tension reached $\varepsilon_{s}=0.015$, whichever occurred first. Ideal yield displacement values $\left(\Delta_{y}\right)$ were found to be 173, 137, and $112 \mathrm{~mm}$ for test columns M123005, M121505, and M101510, respectively. In this paper, displacement values $(\Delta)$ were normalized by the ideal yield displacement $\left(\Delta_{y}\right)$ and termed as displacement ductility $\left(\mu_{\Delta}=\Delta / \Delta_{y}\right)$. Test progress was assessed in terms of $\mu_{\Delta}$. The highest 
lateral displacement to which columns M123005, M121505, and M101510 were tested was 508 $\mathrm{mm}\left(\mu_{\Delta}=2.9\right), 480 \mathrm{~mm}\left(\mu_{\Delta}=3.5\right)$, and $447 \mathrm{~mm}\left(\mu_{\Delta}=4\right)$, respectively.

\subsection{Instrumentation}

The test columns were instrumented to measure average flexural curvature and lateral deformation profiles along the height. Flexural curvatures were monitored at 15, 20 and 20 sections along the height of columns M123005, M121505 and M101510, respectively. A pair of vertically oriented displacement transducer (DT) at two opposite sides was used to calculate the average curvature along each segment of the column. Horizontal DTs were employed to measure the lateral displacement and the deformed shape of the test columns at 7 elevations along the columns' height. The instrumentation layout of column M101510 is illustrated in Fig. 2 (b). The servo-controlled hydraulic actuator used to apply lateral loads was equipped with a load cell that measured the applied force. Experimental profiles of curvature, moment, and displacement along the test columns' height were extracted from the measurements of the aforementioned instruments. These profiles were utilized to experimentally assess the length of the plastic region $\left(L_{p r}\right)$ and effect of slenderness on $L_{p r}$.

\section{Test Results}

\subsection{Curvature Profile}

Curvature profiles were calculated from the relative vertical extensions and contractions, measured by the vertical DTs, between multiple sections along the height. The average (from push and pull directions) curvature profiles along the test columns are shown in Fig. $\mathbf{3}$ (a). The plastic region length, $L_{p r}$, was found from the length of the region over which the curvature values exceeded the yield curvature $\left(\phi_{y}\right)$, indicated by a vertical dashed line in Fig. 3 (a). In this paper the use of the curvature profiles for assessing the extent of the plastic region is denoted by 
experimental method (1), which has been found to be a reliable way to determine $L_{p r}[12,13]$. Yet, a drawback of this method is the difficulty of determining the contribution from various sources to the spread of plasticity, e.g., primary moment gradient, $\mathrm{P}-\Delta$ effect, nonlinear $\mathrm{P}-\delta$ moment, and tension shift effect, since the curvature profiles cannot be broken down into their components.

\subsection{Deformation Profile}

Lateral displacement of the test columns, which was monitored at 7 sections along the height, was used to measure the bending deformation of the columns away from their chord-line $(\delta)$. Bending deformation of the test columns is illustrated in Fig. 3 (b), from which the magnitude of P- $\delta$ moment was estimated. Nonlinear moment profiles were consequently constructed by adding the P- $\delta$ moment to the linear distributions.

\subsection{Bending Moment Profile}

Experimental distribution of the bending moments along the height of the test units was calculated using the deformed geometry of the columns in conjunction with the applied forces measured at the top of the cantilever columns, which is schematically depicted in Fig. 1. The linear primary moment $\left(M_{p}\right)$ without second-order effects was obtained according to $M_{p}=V(L-h)$ where $V$ is the lateral force applied to the top of the column by the horizontal actuator, $L$ is the total height of the column from the base to the center of the top loading block, and $h$ is the height of the monitored section from the base. Additional moment demands due to $\mathrm{P}-\Delta$ and $\mathrm{P}-\delta$ were respectively estimated by $M_{P-\Delta}=P \Delta$ and $M_{P-\delta}=P \delta$. Following this method, experimental profiles of linear moment $\left(M_{L}=M_{p}+M_{P-4}\right)$ and nonlinear moment $\left(M_{N L}=M_{p}+M_{P-\Delta}+M_{P-\delta}\right)$ along the columns' height were constructed from the test data at different displacement ductility levels.

The nonlinear moment gradients, which include the additional moments due to P- $\delta$ effect, are depicted in Fig. 3 (c), in which the yield moment $\left(M_{y}\right)$ is shown by a vertical dashed line. The 
extent of the plastic region due to nonlinear moment gradients $\left(L_{p r, N L}\right)$ with $\mathrm{P}-\delta$ moments included was estimated by the length of the region over which the $M_{N L}$ exceeded the yield moment $\left(M_{y}\right)$. Similarly, the length of the plastic region due to linear moment gradients $\left(L_{p r, L}\right)$, i.e., with P- $\delta$ effects ignored, was the length of the region over which $M_{L}$ exceeded $M_{y}$. In this paper, experimental values of $L_{p r}$ obtained from the moment profiles were denoted as method (2). Depending on the type of the moment profiles from which $L_{p r}$ values were derived, the results were marked by w/ $\mathrm{P}-\delta$ and w/o $\mathrm{P}-\delta$ for nonlinear and linear moment gradients, respectively. Method (2) offered the possibility of decomposing $L_{p r}$ into its components to find the contribution $\mathrm{P}-\delta$ moments as well as tension shift effect.

\subsection{Moment-Curvature Response}

Sectional analyses were conducted to predict the moment-curvature $(M-\phi)$ response of the test columns. Fiber-discretized RC sections with different nonlinear constitutive models for confined concrete, cover concrete and steel reinforcement were used to capture the combined effect of axial load and bending moment. A force-based formulation, as per Spacone et al. [28], was utilized to obtain a stable $M-\phi$ response in case of loss of strength due to softening response. The effect of confinement by the transverse reinforcement on the compressive response of the core concrete was considered following the methods by Mander et al. [29] and Chai [30]. The uniaxial constitutive relation proposed by Mander [31] for steel was implemented to define the post-yield hardening response. Standard material tests were carried out on concrete and steel samples and the results were used to define the parameters for the constitutive models.

Moment-curvature responses for the test columns are shown in Fig. 4 in which the overlaid test data verifies the accuracy of the sectional analyses. Also shown on the plots is the yield point $\left(\phi_{y}, M_{y}\right)$ that was used to estimate $L_{p r}$ from experimental curvature and moment profiles. The yield 
curvature, $\phi_{y}$, was calculated according to the method by Priestley et al. [27]; yet, $M_{y}$ was adjusted to lay on the actual $M-\phi$ curve. The adjusted $M_{y}$ allowed a coherent treatment of curvature and moment profiles that produced consistent results for the extent of the plastic region $\left(L_{p r}\right)$. Results from moment-curvature analyses on the test columns are provided in Table 2. A detailed discussion on the effect of yield properties for predicting structural responses of RC columns can be found in reference [32].

\section{Discussions and Test Results for $L_{p r}$}

\subsection{Experimental Evaluation of $L_{p r}$}

Previous experimental research on determining the length of the critical plastic region used either visual evaluation of the damaged region $[33,34]$ or curvature profiles along the columns' height $[12,13,35]$. In addition to the aforementioned methods, moment profiles are utilized in this paper to assess $L_{p r}$ and its components.

\subsubsection{Method (1): Using Curvature Profiles}

Spread of plasticity along the columns was assessed by using the distribution of curvatures along their height. Accordingly, the extent of the plastic region at the end of each loading cycle $\left(\mu_{\Delta}=1.5,2,3,3.5\right.$, and 4$)$ was determined from the corresponding curvature profiles, as depicted in Fig. 5. The evolution of $L_{p r}$ obtained from curvature profiles, method (1), is plotted in Fig. 6 against the deformation progress of the tests. It can be seen that the plastic region approximately begins at $\mu_{\Delta}=1$ and extends to higher elevations as the lateral displacement increases.

\subsubsection{Method (2): Using Moment Profiles}

In this method $L_{p r}$ was determined from the length of the portion of the column over which the nonlinear moment profile exceeded the yield moment $\left(M_{y}\right)$. Evolution of $L_{p r}$ by this method, with P- $\delta$ effects included, with respect to $\mu_{\Delta}$ is depicted in Fig. 6. Also shown is the extent of the plastic 
region from method (2) when $\mathrm{P}-\delta$ moments are ignored. It can be seen that $L_{p r}$ from nonlinear moment profiles (w/ P- $\delta$ ) closely follow the results from curvature profiles (method (1)). The small difference between $L_{p r}$ values from methods (1) and (2) with P- $\delta$ is mainly caused by non-flexure mechanisms, such as tension shift, that contribute to the spread of plasticity.

Results from linear moment gradients (w/o P- $\delta$ ) significantly underestimated the $L_{p r}$ values obtained from method (1). This emphasizes the importance of considering nonlinear moment gradients and P- $\delta$ effects for estimating the extent of the plastic region.

\subsubsection{Method (3): Using Visual Observation}

Visual evaluation of cover spalling was also used to estimate the damage zone on the test columns. The length of the spalling region $\left(L_{s}\right)$ was measured and recorded during tests at different displacement ductility levels. Values for $L_{p r}$ were then estimated assuming that the observable damage zone matches the critical plastic region, as depicted by Fig. 5 in which $L_{p r}$ values from method (1) are marked at different displacement ductility levels along with the extent of the observed spalling zone $\left(L_{s}\right)$. It can be seen that the plastic region extended beyond the region with observable damage. The ineffectiveness of evaluating damage zone to estimate $L_{p r}$ from the experiments is also illustrated by Fig. 6, where results from the visual evaluation of spalling damage are depicted as method (3). It can be seen that method (3) dramatically underestimates the extent of the plastic region. While previous research has found correlations between the extent of the spalling region $\left(L_{s}\right)$ and $L_{p r}$ in non-slender columns [13], such correlation was not found in the slender columns tested by the authors. Thus, visual inspection of the cover damage cannot always serve as a method for experimental evaluation of the extent of the plastic region, i.e., $L_{s} \neq L_{p r}$. Due to the discrepancy between $L_{p r}$ and $L_{s}$, results obtained from methods (1) and (2) were chosen for further analysis. 


\subsection{Components of $L_{p r}$}

It is essential to identify the components of $L_{p r}$ and their contribution to the extent of plasticity on RC columns in order to assess the effects of slenderness. The main contributors to $L_{p r}$ are the linear moment gradient (defined as the sum of primary and P- $\Delta$ moments), the tension shift effect and the $\mathrm{P}-\delta$ moment due to column bending away from the chord line. It is worth mentioning that strain-penetration, which is a main component in plastic hinge $\left(L_{p}\right)$ models, mainly contributes to the extent of the plastic region into the footing (or adjacent RC member). Therefore, the extent of plasticity along the columns height is not directly affected by strain-penetration. The influence of major contributors to $L_{p r}$ is shown in Fig. 7, in which the darkest area represents the extent of the plastic region due to linear moment gradient. The section in the middle is the contribution of P- $\delta$ moments to $L_{p r}$ and the region with the lightest shade shows the spread of plasticity caused by nonflexural mechanisms including shear effects. It is worth noting that the primary moment $\left(M_{p}\right)$ does not reach the yield limit if P- $\Delta$ moments are not considered. Therefore, the contribution of $M_{p}$ and P- $\Delta$ moments could not be determined separately.

\subsubsection{Effect of Tension Shift on $L_{p r}$}

The extent of the plastic region due to tension shift effect $\left(L_{t s}\right)$ was predicted for the test columns according to the method by Hines et al. [12]. The crack angle was calculated by estimating the direction of the principal tensile stress according to Collins and Mitchell [36]. The crack angle predicted for the test columns is plotted against $\mu_{\Delta}$ in Fig. 8 (a), in which the plots begin at the displacement ductility corresponding to the start of cracking. It can be seen that crack angles are small, i.e., cracks are primarily perpendicular to the columns' longitudinal axis. Unlike the inclined cracks in RC members with strong shear effects, the nearly perpendicular cracks in flexuredominated slender columns contribute marginally to the extent of the plastic region due to tension 
shift $\left(L_{t s}\right)$, which is plotted against displacement ductility in Fig. 8 (b). Small crack angles were experimentally verified by inspecting the crack patterns on the test columns, as shown in Fig. 5. The contribution of tension shift on extending the plastic region was experimentally measured by the difference between the experimental $L_{p r}$ from methods (1) and (2) with P- $\delta$ moments included. The difference provided the extent of the plastic region due to mechanisms other than moment gradients, such as tension shift. The experimental results for the effect of tension shift on the plastic region $\left(L_{t s} / L_{p r}\right)$ are compared against the predictions of the shear crack model by Hines et al. [12] in Fig. 9 (a). Satisfactory agreement between the test data and the analysis results verifies the model's accuracy in assessing the tension shift effect on RC columns. It can be concluded from the results presented in Fig. 9 (a) that $L_{p r}$ on the test columns is not considerably affected by the tension shift effect.

\subsubsection{Effect of $P-\delta$ on $L_{p r}$}

The effects of slenderness and the associated member flexibility on $L_{p r}$ were assessed through the contribution of $\mathrm{P}-\delta$ moments $\left(L_{p r, P-\delta}\right)$. Comparison of the results obtained according to method (2) from linear $\left(M_{L}\right)$ and nonlinear $\left(M_{N L}\right)$ moment profiles demonstrated the increase of the plastic region due to P- $\delta$. Therefore, $L_{p r, P-\delta}$ was experimentally determined according to $\left(L_{p r, N L}-L_{p r, L}\right)$. To illustrate the contribution of moment nonlinearity to the spread of plasticity, the ratio $L_{p r, P-\delta} / L_{p r}$ is plotted in Fig. 9 (b). It can be seen that, on average, P- $\delta$ moments account for $20 \%$ of the total $L_{p r}$. Also shown is the effect of $\mathrm{P}-\delta$ on $L_{p r}$ as predicted by a nonlinear mechanics-based solution [32]. This topic is discussed later in this paper. 


\section{Comparison of Experimental $L_{p r}$ with Previous Research}

Current knowledge about the extent of the plastic region due to moment gradient is reevaluated herein for slender RC columns in light of the new experimental evidence from the tests conducted by the authors.

\subsection{Comparison with Current Design Guidelines}

Design guidelines often provide recommendations for the largest extent of the plastic region at the ultimate limit state of the RC column. None of the columns tested by the authors reached their ultimate failure, defined by the ultimate curvature ductility, since the lateral displacement was limited by the actuator stroke $(508 \mathrm{~mm})$. However, the test units reached the stability limits found in the literature $[6,9,37,38]$. Experimental $L_{p r}$ at displacement ductility levels $\left(\mu_{\Delta}\right)$ that correspond to the onset of instability defined by ACI [9], Eurocode 8 for buildings [6], Pettinga and Priestley [37], and Silva et al. [38] were compared against the length of the critical plastic region recommended by the design guidelines with variable $L_{p r}[7,8,10,11]$ as given in Table 3 . Similarly, a comparison of design guidelines that recommend a constant length for the critical region $[5,6,9]$ is provided in Table 4 . It is worth noting that the design guidelines that define $L_{p r}$ according to the moment distribution along the column were implemented using both linear (w/o $\mathrm{P}-\delta$ ) and nonlinear (w/ P- $\delta$ ) moment profiles and the results were compared separately against the experimental data. Percentage errors (PE) for the code-specified values of $L_{p r}$ were calculated at four different displacement ductility levels, corresponding to the aforementioned stability limits. A review of the error values listed in Table 3 and Table 4 reveals that the extent of the plastic region on slender RC columns is generally underestimated by current design guidelines. The only exception is the seismic provisions by Caltrans, which yielded a conservative estimate of $L_{p r}$ for all cases. Considering the fact that underestimating the length of the plastic region for special 
detailing potentially risks the ductility of RC columns that are designed to undergo large inelastic deformations, reassessment of the current design guidelines for the case of slender RC columns is vital for a safe seismic design.

Some design guidelines, such as AASHTO, Caltrans, NZS 3101, and Eurocode, recommend a ratio of the maximum moment for predicting $L_{p r}$. The accuracy of this method is affected by the yield to ultimate moment ratio $\left(M_{y} / M_{u}\right)$, with accuracy increasing as the moment ratio approaches the actual value for the column. Larger moment ratios underestimate $L_{p r}$, while smaller moment ratios provide a conservative overestimate. For the columns tested by the authors the average ratio for $M_{y} / M_{u}$ was $72 \%$. Therefore, design guidelines that recommend a $75 \%$ threshold for determining $L_{p r}$ gave more accurate estimates of the extent of the plastic region; whereas design guidelines based on a moment ratio of $80 \%$ did not yield a good prediction, and thus underestimated $L_{p r}$.

It is worth noting that the ACI code limits the maximum displacement ductility of slender columns through a stability limit defined by $\left(M_{p}+M_{P-4}\right) / M_{p}<1.4$. The noted limit restricts the displacement ductility of columns M123005, M121505, and M101510 to 2.5, 1.8, and 1.4, respectively. As seen from the results in Table 4, the ACI code successfully predicted $L_{p r}$ on the test columns with a 7\% average error at the maximum permitted $\mu_{\Delta}$. Therefore, it can be inferred the extent of the plastic region specified by the ACI code is consistent with the maximum permitted displacement ductility.

The same can be said about the seismic provisions by Caltrans, which limits the displacement ductility of single column bents to 4 . Comparing the experimental $L_{p r}$ with the value prescribed by the Caltrans guidelines indicates that the code recommended $L_{p r}$ is a conservative estimate for $\mu_{\Delta}$ levels less than 4. In contrast, some of the design guidelines studied in this paper were inconsistent 
between the maximum allowable displacement ductility and the extent of the recommended plastic region. Eurocode 8 for buildings [6] allows RC columns to reach the stability limit defined by $(P \cdot \Delta) /(V \cdot L)=0.3$. The noted limit respectively corresponds to $\mu_{\Delta}=3,2.3$, and 1.7 for columns M123005, M121505, and M101510. However, results in Table 4 show that the length of the plastic region specified by Eurocode 8 for buildings significantly underestimates the test values. The inconsistency also exists in Eurocode 8 for bridges [7], which limits $\mu_{\Delta}$ to 3.5 for RC columns with aspect ratios greater than 3. Results in Table $\mathbf{3}$ show that the length of the plastic region according to Eurocode 8 for bridges does not cover the entire $L_{p r}$ from the experiments at displacement ductility levels less than 3.5. Inconsistency between the maximum $\mu_{\Delta}$ and the recommended $L_{p r}$ potentially imperils the reliability of RC columns by allowing large inelastic deformations while failing to impose the necessary transverse reinforcement required for a ductile inelastic response along the entire length of the critical plastic region.

It is worth noting that the aforementioned stability limits were based on a second-order analysis that considers $\mathrm{P}-\Delta$ effects. Most specification codes provide additional limits, which are more conservative than the stability limits discussed in this paper, if first order analyses are conducted and second-order effects (including P- $\Delta$ moments) are ignored. These two limits, which usually apply to the same stability index parameter, should not be confused with each other since the more conservative limit applies to first-order analyses. In this paper, stability limits for a second-order analysis that captures P- $\Delta$ effect were considered.

\subsection{Comparison with Current Expressions}

Expressions for $L_{p r}$ and $L_{p}$ from previous research were reassessed by comparing them against the experimental $L_{p r}$ values for the test columns reported here as shown in Table 5. The shear crack model by Hines et al. [12] was used to predict the extent of the plastic region on the test 
columns. Further, the moment gradient component from commonly used plastic hinge models [2123] was extracted using Eq. (1) and is compared against the experimental $L_{p r}$. Percent errors (PE) were computed for the models studied and the shear crack model has a superior performance even though it significantly underestimates $L_{p r}$. The additional spread of plasticity not captured by the shear crack model was caused by the nonlinear moment gradient from P- $\delta$ effects, as it is discussed later in this paper. Furthermore, the anticipated discrepancy between the experimental $L_{p r}$ and the moment gradient component of the plastic hinge $\left(L_{p}\right)$ models confirms the lack of direct correspondence between the length of the plastic hinge $\left(L_{p}\right)$ and the physical extent of the plastic region $\left(L_{p r}\right)$.

\section{Proposed Expression for $L_{p r}$}

The development of an expression for the extent of the plastic region due to linear moment gradient $\left(L_{p r, L}\right)$ is presented. The $L_{p r, L}$ expression can be adjusted for the effect of member deformation and nonlinear moment gradient due to P- $\delta$ effect. Consequently, a closed-form relationship between $L_{p r, N L}$ and $\mu_{\Delta}$ is also proposed.

\section{1. $L_{p r}$ due to Linear Moment Gradient $\left(L_{p r}, L\right)$}

Lateral displacement of a column after yield can be assumed to equal the sum of displacements from elastic deformations $\left(\Delta_{y}\right)$ along the entire length and plastic deformations $\left(\Delta_{p}\right)$ from plastic rotations (about the base) over the plastic region $\left(L_{p r, L}\right)$.

$$
\begin{gathered}
\Delta_{y}=\frac{\phi_{y} L^{2}}{3} \\
\Delta_{p}=L\left(\phi-\phi_{y}\right) \frac{L_{p r, L}}{2}
\end{gathered}
$$

Combining Eq. (2) and Eq. (3), a relationship between displacement ductility $\left(\mu_{\Delta}\right)$ and curvature ductility $\left(\mu_{\phi}=\phi / \phi_{y}\right)$ was obtained as given by Eq. (4). 


$$
\mu_{\Delta}=\left(\mu_{\phi}-1\right) \frac{3 L_{p r, L}}{2 L}+1
$$

A bilinear plot for the $M-\phi$ response of RC section is assumed such that the initial branch starts from the origin and ends at the yield point $\left(\phi_{y}, M_{y}\right)$ and the post-yield branch connects the yield point to the ultimate curvature $\left(\phi_{u}\right)$ and moment $\left(M_{u}\right)$. The slope of the pre-yield branch $\left(E I_{e l}\right)$, commonly known as the effective stiffness of the cracked section, is defined by $E I_{e l}=M_{y} / \phi_{y}$. Similarly, the slope of the post-yield branch of the $M-\phi$ response is found according to $E I_{\text {in }}=\left(M_{u}\right.$ - $\left.M_{y}\right) /\left(\phi_{u}-\phi_{y}\right)$. Accordingly, the relationship between curvature ductility $\left(\mu_{\phi}\right)$ and moment overstrength $\left(\Omega_{M}=M / M_{y}\right)$ was found as given by Eq. (5) where $n^{2}\left(=E I_{e l} / E I_{i n}\right)$ is the ratio of the pre-yield effective flexural stiffness $\left(E I_{e l}\right)$ to the post-yield slope of $M-\phi$ bilinear response $\left(E I_{i n}\right)$.

$$
\mu_{\phi}=n^{2}\left(\Omega_{M}-1\right)+1
$$

Assuming a linear moment gradient that starts at zero from point of contra-flexure and reaches the maximum moment at a distance $L$, the extent of the plastic region $\left(L_{p r, L}\right)$ along the column height is related to the moment overstrength $\left(\Omega_{M}\right)$ according to Eq. (6).

$$
L_{p r, L}=L\left(1-\frac{1}{\Omega_{M}}\right)
$$

Solving Eq. (6) for $\Omega_{M}$ results in Eq. (7).

$$
\Omega_{M}=\frac{L}{L-L_{p r, L}}
$$

By combining Eq. (7) and Eq. (5) and then substituting into Eq. (4), the relationship between $L_{p r, L}$ and $\mu_{\Delta}$ was determined (Eq. (8)).

$$
\mu_{\Delta}=n^{2}\left(\frac{L_{p r, L}}{L-L_{p r, L}}\right) \frac{3 L_{p r, L}}{2 L}+1
$$


Rearranging Eq. 8 provides a binomial equation that always has a positive root for $L_{p r, L}$. Therefore, the solution to the extent of the plastic region due to a linear moment gradient $\left(L_{p r, L}\right)$ as a function of displacement ductility $\left(\mu_{\Delta}\right)$ was found as noted in Eq. (9).

$$
L_{p r, L}=L\left[\sqrt{\left(\frac{\mu_{\Delta}-1}{3 n^{2}}\right)^{2}+2\left(\frac{\mu_{\Delta}-1}{3 n^{2}}\right)}-\left(\frac{\mu_{\Delta}-1}{3 n^{2}}\right)\right]
$$

It is worth noting that the length of the plastic region is meaningful after yield. Therefore, Eq. (9) is valid for displacement ductility levels greater than $1\left(\mu_{\Delta} \geq 1\right)$.

\section{2. $L_{p r}$ due to Nonlinear Moment Gradient $\left(L_{p r, N L}\right)$}

Previous research by the authors [32] demonstrated that the $L_{p r, L}$ from a linear moment gradient can be adjusted to account for the effect of P- $\delta$ moment using an elastic slenderness parameter $\left(\kappa_{e l}{ }^{2}\right.$ $\left.=P L^{2} / E I_{e l}\right)$ according to $L_{p r, N L}=L_{p r, L}\left(1+\kappa_{e l}^{2} / 3\right)$. Therefore, the extent of the plastic region due to a nonlinear moment gradient $\left(L_{p r, N L}\right)$ is given by Eq. (10).

$$
L_{p r, N L}=L\left[\sqrt{\left(\frac{\mu_{\Delta}-1}{3 n^{2}}\right)^{2}+2\left(\frac{\mu_{\Delta}-1}{3 n^{2}}\right)}-\left(\frac{\mu_{\Delta}-1}{3 n^{2}}\right)\right]\left(1+\frac{\kappa_{e l}^{2}}{3}\right)
$$

It is worth mentioning that Eq. (10) provides the extent of the plastic region due to a nonlinear moment gradient. Therefore, the effect of tension shift on $L_{p r}$ is not included in Eq. (10); albeit moment gradient is the main contributor to $L_{p r}$ in slender ductile RC columns.

\subsection{Verification of the Proposed Formula}

The length of the plastic region for the test columns at different displacement ductility levels determined with Eq. (10) are provided in Table 5. The parameters for Eq. (10) were computed from the moment-curvature analysis results. As seen from the mean absolute percent errors (MAPE) in Table 5 the proposed formula is a simple and accurate way to estimate of the extent of the plastic region on flexure-dominated slender RC columns. The model by Hines et al. [12] 
predicted $L_{p r}$ for the test columns with $27 \%$ error, and the moment gradient component from current $L_{p}$ models underestimated $L_{p r}$ by $54 \%$. Conversely, the proposed formula predicted $L_{p r}$ with $16 \%$ error.

The mean absolute percent error (MAPE) values were calculated for the $L_{p r}$ from design guidelines and from Eq. (10), and were compared in Table 6. Further, the error measures corresponding to the use of different design guidelines were calculated separately and presented in Fig. 10 (a). The numbers above the bar groups represent the average error for the three test columns. It can be seen that the proposed formula offers a more accurate estimate of $L_{p r}$ at different levels of displacement ductility than current design guidelines.

The authors acknowledge that the recommendations in seismic design codes are not meant to precisely predict $L_{p r}$. Nonetheless, it is essential for design guidelines to require the length of the potential plastic region for special detailing to be conservatively larger than the maximum $L_{p r}$ from experiments to guarantee a ductile flexural inelastic response. Therefore, the highest elevation to which the plastic region on the test columns reached (maximum $L_{p r}$ ) was compared against the length of the plastic region recommended in seismic codes. The absolute percent error (APE) associated with the code-recommended plastic region is illustrated in Fig. 10 (b). Also included in Fig. 10 (b) is the error from the proposed formula (Eq. (10)) calculated at the highest displacement ductility to which the columns were tested. It can be seen that Eq. (10) predicts the maximum $L_{p r}$ with reasonable accuracy.

An exception to the superior performance of the proposed model is the case of column M101510, in which the experimental maximum $L_{p r}$ showed better correlation with Caltrans design guidelines than Eq. (10). Different factors could have contributed to the larger error for column M101510. Lower aspect ratio, which potentially increases the effect of non-flexural actions on the 
extent of the plastic region, is a key factor. Better correlation with the Caltrans design guidelines can be explained by the fact that they require a constant plastic region equal to $1 / 4$ of the length (shear span, $L$ ), which is the highest ratio for $L_{p r} / L$ among all the specification codes studied in this paper. While for most column configurations $L / 4$ is a conservative overestimate of the actual extent of the plastic region $\left(L_{p r}\right)$, it yields a better prediction in the case of column M101510. This is mainly a coincidence since assuming the extent of the plastic region as one-fourth of the shear span regardless of the aspect ratio, axial load ratio, longitudinal and transverse reinforcement ratio, etc., is a rough treatment of the issue. The proposed model, however, takes into account different geometrical and structural properties of the column and adjusts the extent of the plastic region accordingly. To avoid such non-conservative underestimates of $L_{p r}$ from the proposed model, as was the case for column M101510, Eq. (10) must be increased by a factor of safety obtained from an exhaustive survey of previously tested RC columns before being used as a design guideline.

It should be noted that not only is Eq. (10) capable of predicting the extent of the plastic region at the ultimate state (maximum $L_{p r}$ ), but it also accurately follows the spread of the plastic region along the columns' height due to increasing inelastic deformations $\left(\mu_{\Delta}\right)$. To demonstrate it the trends of experimental and predicted $L_{p r}$ were compared. The experimental extents of the plastic region $\left(L_{p r}\right)$ with respect to displacement ductility $\left(\mu_{\Delta}\right)$ from method $(2)$ with and without P- $\delta$ effect are plotted in Fig. 11. Equation (10) is also plotted to compare against experimental data. Results from the shear crack model by Hines et al. [12] are plotted as well. It can be seen that Eq. (10) correlates well with the experimental data extracted from the nonlinear moment gradient in which $\mathrm{P}-\delta$ effects were included. The shear crack model is shown to capture the extent of the plastic region due to linear moment gradient, i.e., if $\mathrm{P}-\delta$ moments are ignored. Thus, the plots in Fig. 11 show that Eq. (10) accurately predicts $L_{p r}$ for a wide range of $\mu_{\Delta}$ levels. 
The proposed model in Eq. (10) for the moment gradient part of $L_{p r}$ is valid for all non-negative slenderness values $\left(\kappa_{e l} \geq 0\right)$ and positive post-yield stiffness ratios $(n>0)$. Yet, the contribution of second-order effects to $L_{p r}$ can be safely ignored for non-slender columns $\left(\kappa_{e l} \leq 0.5\right)$ since for these cases P- $\delta$ moments contribute less than $10 \%$ to the moment gradient portion of $L_{p r}$ and the effects of non-flexural phenomena on $L_{p r}$ become significant.

Despite the very promising performance of the proposed formula for estimating $L_{p r}$ there are some limitations related with its broad application to other RC columns. First, Eq. (10) provides the extent of the plastic region due to moment gradient. Although moment gradient is the primary mechanism for growth of the plastic region in slender columns, shear effects, e.g. tension shift, plays a significant role in shear-dominated, or shorter, columns. It is thus crucial to complement Eq. (10) with additional terms that capture shear effects for extending the applicability of Eq. (10) to a wider range of RC columns. Furthermore, the derivation presented in this paper was based on a positive post-yield $M-\phi$ response, i.e. $E I_{\text {in }}>0$. Almost all RC sections of normal-strength concrete with adequate confinement steel (i.e., designed to modern seismic codes) exhibit a positive postyield stiffness. However, post-yield softening $\left(E I_{\text {in }} \leq 0\right)$ can occur in RC sections with highstrength concrete, with high axial load, or without proper confinement reinforcement for ductile response. For a non-positive post-yield stiffness, the moment gradient does not contribute to the growth of $L_{p r}$ and Eq. (10) becomes irrelevant.

In the proposed expression for $L_{p r}$, the effect of P- $\delta$ moments on extending the plastic region was derived from a closed-form solution to the deformation in cantilever columns using nonlinear elastic beam-column theory $[39,40]$. It was found that the response of RC columns at intermediate displacement ductility levels $\left(\mu_{\Delta} \leq 2.5\right)$ was effectively approximated by an equivalent elastic model. However, the response starts to deviate from the elastic beam-column theory at large 
inelastic deformations $\left(\mu_{\Delta}>2.5\right)$ [32]. Therefore, Eq. (10) introduces an error at large inelastic deformations, albeit the error remains small enough for design purposes.

Lastly, Eq. (10) tends to slightly underestimates $L_{p r}$. It is thus desired to amplify the results from with a factor to provide a conservative estimate of the potential plastic region for special detailing. However, obtaining the proper amplification factor for Eq. (10) requires rigorous statistical analyses on a large array of RC columns. Therefore, a full implementation of the proposed expression for $L_{p r}$ in design guidelines requires further research.

\section{Conclusions}

The extent of the critical plastic region in slender RC bridge columns was experimentally evaluated via test data from three large-scale columns with aspect ratios up to 12. Current design guidelines for the length of the potential plastic region that requires special detailing were reassessed in light of the experimental results reported in this paper and the following conclusions were derived:

1. Use of curvature profiles is the most viable method to experimentally assess the extent of the plastic region $\left(L_{p r}\right)$. Moment profiles can also be used to determine the moment gradient components of $L_{p r}$. However, the length of the damage zone on test columns may not necessarily correlate with the extent of the plastic region. Particularly in slender RC columns, the plastic region tends to spread significantly beyond the observable damage.

2. Experimental results proved that $\mathrm{P}-\delta$ moments increase the extent of the plastic region on slender columns by $22 \%$ on average. Therefore, it is crucial to consider moment nonlinearity due to P- $\delta$ effects for predicting $L_{p r}$ on slender columns. 
3. Tension shift effects on the spread of plasticity for the slender columns reported here were found to be minimal as the plastic region was extended by $6 \%$, on average, due to this effect. This confirms the flexure-dominated response of slender RC columns.

4. Out of seven different seismic design recommendations for the length of the critical plastic region, only those by Caltrans provided a conservative estimate of $L_{p r}$, whereas the other design codes underestimated $L_{p r}$ by $34 \%$. Therefore, slender columns designed according to current codes may not have sufficient transverse reinforcement along the entire length of the potential plastic region.

5. In some design guidelines, such as ACI and Caltrans, recommendations for the length of the critical region are consistent with the maximum displacement ductility level permitted by the same code. That is, the experimental $L_{p r}$ did not exceed the code-specified length except for displacement ductility levels that were beyond the code limit. In contrast, guidelines such as Eurocode 8 for buildings and bridges, allow large inelastic ductility demands while the recommended length for ductile detailing is significantly smaller than the actual plastic region.

6. The shear crack model for $L_{p r}$ by Hines et al. [12] was found capable of predicting the extent of the plastic region if $\mathrm{P}-\delta$ moments are ignored. Therefore, the model can be improved by adding the contribution from P- $\delta$. By contrast, the moment gradient component of commonly used plastic hinge $\left(L_{p}\right)$ models was found to be significantly different from the experimental $L_{p r}$.

7. The proposed expression for $L_{p r}$ (Eq. (10)), which considers a nonlinear moment profile along RC columns' height, is capable of accurately predicting the extent of the plastic region on slender flexure-dominated columns. 


\section{Acknowledgements}

The research described in this paper was carried out with funding from the U.S. National Science Foundation under grant numbers CMMI-1000549 and CMMI-1000797.

\section{List of Abbreviations and Notations}

The following symbols are used in this paper:

\begin{tabular}{|c|c|c|}
\hline$A_{g}$ & $=$ & Gross area of reinforced concrete section \\
\hline APE & $=$ & Absolute percent error \\
\hline$A_{s l}$ & $=$ & Area of longitudinal steel reinforcement \\
\hline$D$ & $=$ & Column section diameter \\
\hline$d_{s h}$ & $=$ & Diameter of transverse reinforcing steel \\
\hline$d_{s l}$ & $=$ & Diameter of longitudinal reinforcing steel \\
\hline DT & $=$ & Displacement transducer \\
\hline$E I_{e l}$ & $=$ & Flexural stiffness of a cracked RC section before yield \\
\hline$E I_{\text {in }}$ & $=$ & Post-yield flexural stiffness of RC section \\
\hline$f_{c}^{\prime}$ & $=$ & Peak compressive strength of unconfined concrete \\
\hline$f_{u l}$ & $=$ & Ultimate strength of longitudinal reinforcing steel \\
\hline$f_{y l}$ & $=$ & Yield strength of longitudinal reinforcing steel \\
\hline$h$ & $=$ & Height of column section from base \\
\hline$L$ & $=$ & Column shear span \\
\hline$L_{p}$ & $=$ & Plastic hinge length \\
\hline$L_{p r}$ & $=$ & Length of the critical plastic region (also known by $l_{o}, l_{c r}, l_{y}, l_{h}$ ) \\
\hline$L_{p r, L}$ & $=$ & Length of the plastic region from a linear moment gradient \\
\hline
\end{tabular}




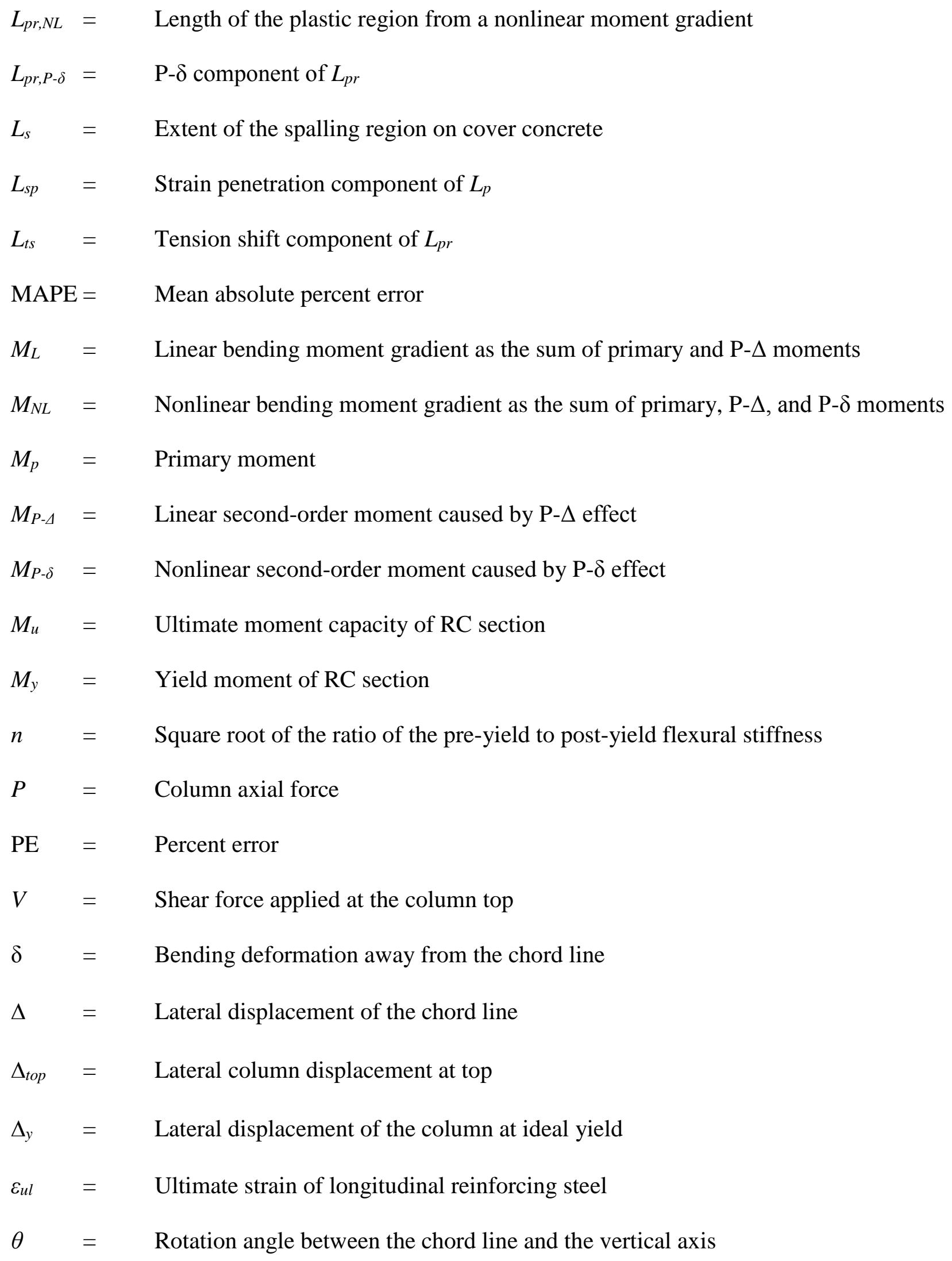




$\begin{array}{lll}\kappa_{e l} & = & \text { Slenderness parameter } \\ \mu_{\Delta} & = & \text { Displacement ductility } \\ \mu_{\phi} & = & \text { Curvature ductility } \\ \rho_{s h} & = & \text { Volumetric transverse steel reinforcement ratio } \\ \rho_{s l} & = & \text { Longitudinal steel reinforcement ratio } \\ \phi_{u} & = & \text { Ultimate curvature capacity of RC section } \\ \phi_{y} & = & \text { Yield curvature of RC section } \\ \Omega_{M} & = & \text { Moment overstrength }\end{array}$




\section{References}

[1] Applied Technology Council, ATC-32. Improved seismic design criteria for california bridges: Provisional recommendations. Redwood City (CA); 1996.

[2] Priestley MJN, Seible F, Calvi GM. Seismic design and retrofit of bridges. John Wiley \& Sons, Inc.; 1996.

[3] Transportation Research Board, Synthesis 440. Performance-Based Seismic Bridge Design. National Cooperative Highway Reserach Program. Washington D.C.; 2013.

[4] Lee C, Filippou FC. Efficient Beam-Column Element with Variable Inelastic End Zones. Journal of Structural Engineering. 2009;135(11):1310-9.

[5] Canadian Standard Association. Design of Concrete Structures. CAN/CSA-A23.3-04. Mississauga, Ontario (Canada); 2004.

[6] CEN. Eurocode 8: Design of Structures for Earthquake Resistance. Part 1: General Rules, Seismic Actions and Rules for Buildings. EN 1198-1. Brussels (Belgium): European Committee for Standardization; 2004.

[7] CEN. Eurocode 8: Design Provisions of Structures for Earthquake Resistance. Part 2: Bridges. EN 1998-2. Brussels (Belgium): European Committee for Standardization; 2005.

[8] NZS 3101. The Design of Concrete Structures. Concrete Structures Standard, Part 1: Code of Practice, Wellington (New Zealand): New Zealand Standard; 2006.

[9] ACI Committee 318. Building Code Requirements for Structural Concrete (ACI 318-11) and Commentary (ACI 318R-11). Farmington Hills (MI): American Concrete Institute; 2011.

[10] AASHTO. Guide Specifications for LRFD Seismic Bridge Design. Washington, D.C.: American Association of State Highway and Transportation Officials; 2011.

[11] Caltrans. Seismic Design Criteria 1.7. California Department of Transportation; 2013. 
[12] Hines EM, Restrepo JI, Seible F. Force-displacement characterization of well-confined bridge piers. ACI Structural Journal. 2004;101:537-48.

[13] Pam HJ, Ho JCM. Length of critical region for confinement steel in limited ductility highstrength reinforced concrete columns. Engineering Structures. 2009;31:2896-908.

[14] Paulay T, Priestley MJN. Seismic Design of Reinforced Concrete and Masonry Buildings. New York (NY): Wiley; 1992.

[15] Zhao X-M, Wu Y-F, Leung AYT. Analyses of plastic hinge regions in reinforced concrete beams under monotonic loading. Engineering Structures. 2012;34:466-82.

[16] Mortezaei A, Ronagh HR. Plastic hinge length of FRP strengthened reinforced concrete columns subjected to both far-fault and near-fault ground motions. Scientia Iranica. 2012;19:1365-78.

[17] Barrera AC, Bonet JL, Romero ML, Miguel PF. Experimental tests of slender reinforced concrete columns under combined axial load and lateral force. Engineering Structures. 2011;33:3676-89.

[18] Baker ALL, Amarakone AMN. Inelastic Hyperstatic Frames Analysis. Flexural Mechanics of Reinforced Concrete. 1964;SP-12:85-142.

[19] Mendis P. Plastic Hinge Lengths of Normal And High-strength Concrete In Flexure. Advances in Structural Engineering. 2001;4(4):189-95.

[20] Zhao X, Wu Y-F, Leung AY, Lam HF. Plastic Hinge Length in Reinforced Concrete Flexural Members. Procedia Engineering. 2011;14:1266-74.

[21] Priestley MJN, Park R. Strength and ductility of concrete bridge columns under seismic loading. ACI Structural Journal. 1987;84:61-76. 
[22] Bae S, Bayrak O. Plastic hinge length of reinforced concrete columns. ACI Structural Journal. 2008;105:290-300.

[23] Berry MP, Lehman DE, Lowes LN. Lumped-Plasticity Models for Performance Simulation of Bridge Columns. ACI Structural Journal. 2008;105:270-9.

[24] Dowell RK, Hines EM. Plastic Hinge Length of Reinforced Concrete Bridge Columns. Proceedings of the Third National Seismic Conference and Workshop on Bridges and Highways. Portland (OR). 2002.

[25] Burgueño R, Babazadeh A, Silva PF. Second-order Effects on the Seismic Response of Slender Bridge Columns. ACI Structural Journal. 2015. (in press)

[26] Lehman D, Moehle J, Mahin S, Calderone A, Henry L. Experimental Evaluation of the Seismic Performance of Reinforced Concrete Bridge Columns. Journal of Structural Engineering. 2004;130:869-79.

[27] Priestley MJN, Calvi GM, Kowalsky MJ. Displacement-based Seismic Design of Structures. Pravia, Italy: IUSS Press; 2007.

[28] Spacone E, Filippou FC, Taucer FF. Fibre Beam-Column Model for Non-Linear Analysis of R/C Frames: Part I. Formulation. Earthquake Engineering \& Structural Dynamics. $1996 ; 25: 711-25$.

[29] Mander J, Priestley M, Park R. Theoretical Stress - Strain Model for Confined Concrete. Journal of Structural Engineering. 1988;114:1804-26.

[30] Chai YH. Steel jacketing of circular reinforced concrete bridge columns for enhanced flexural performance [Ph.D. Thesis]: University of California, San Diego (CA); 1991.

[31] Mander J. Seismic design of bridge piers. [Ph.D. Thesis]: University of Canterbury (New Zealand); 1984. 
[32] Babazadeh A, Burgueño R, Silva PF. P- $\delta$ Effects on the Plastic Region of RC Bridge Columns: A Closed-form Solution. Journal of Structural Engineering. 2015. (in review)

[33] Bae S, Bayrak O. Seismic Performance of Full-Scale Reinforced Concrete Columns. ACI Structural Journal. 2008;105:123-33.

[34] Paultre P, Eid R, Robles HI, Bouaanani N. Seismic Performance of Circular High-Strength Concrete Columns. ACI Structural Journal. 2009;106:395-404.

[35] Khaled A, Massicotte B, Tremblay R. Cyclic Testing of Large-Scale Rectangular Bridge Columns under Bidirectional Earthquake Components. Journal of Bridge Engineering. 2011;16:351-63.

[36] Collins MP, Mitchell D. Prestressed concrete structures. Toronto (Canada): Response Publications; 1997.

[37] Pettinga JD, Priestley MJN. Accounting for p-delta effects in structures when using direct displacement-based design. The 14th World Conference on Earthquake Engineering Beijing (China); 2007.

[38] Silva PF, Sangtarashha A, Burgueño R. P-Delta Effects in Limit State Design of Slender RC Bridge Columns. 15th WCEE World Conference on Earthquake Engineering. Lisbon (Portugal); 2012.

[39] Chen WF, Atsuta T. Theory of Beam-Columns, Volume 1: In-Plane Behavior and Design. Fort Lauderdale (FL): J. Ross Pub.; 2007.

[40] Galambos TV, Surovek AE. Structural Stability of Steel: Concepts and Applications for Structural Engineers. Hoboken (NJ): John Wiley \& Sons, Inc.; 2008. 


\section{List of Tables and Figures}

\section{List of Tables}

Table 1 Geometrical and material properties of test columns

Table 2 Results from moment-curvature analyses

Table 3 Comparison between experimental $L_{p r}$ and design guidelines with variable $L_{p r}$

Table 4 Comparison of experimental $L_{p r}$ against design guidelines with constant $L_{p r}$

Table 5 Comparison of experimental $L_{p r}$ against current $L_{p r}$ and $L_{p}$ models

Table 6 Summary of the error in predicting $L_{p r}$ in test columns

\section{List of Figures}

Fig. 1. Effect of nonlinear moment profile and $\mathrm{P}-\delta$ on the extent of the plastic region $\left(L_{p r}\right)$

Fig. 2. Test setup, reinforcement, and instrumentation layout of test columns

Fig. 3. Experimental profiles of curvature, deformation, and nonlinear moment on test columns

Fig. 4. Experimental and numerical moment-curvature $(M-\phi)$ responses of test columns

Fig. 5. Extents of the plastic region $\left(L_{p r}\right)$ and spalling zone $\left(L_{s}\right)$ depicted along the test columns at multiple displacement ductility levels

Fig. 6. Extent of the plastic region $\left(L_{p r}\right)$ extracted from the experiments

Fig. 7. Major contributors to $L_{p r}$

Fig. 8. Predicted crack angle and the associated tension shift effect on test columns

Fig. 9. Extents of the plastic region due to tension shift effect $\left(L_{t s}\right)$ and P- $\delta$ moment $\left(L_{p r, \mathrm{P}-\delta}\right)$

Fig. 10. Error associated with the length of the critical plastic region from design codes

Fig. 11. Comparison of the proposed formula for $L_{p r}$ against the model by Hines et al. [12] 


\section{Figures}

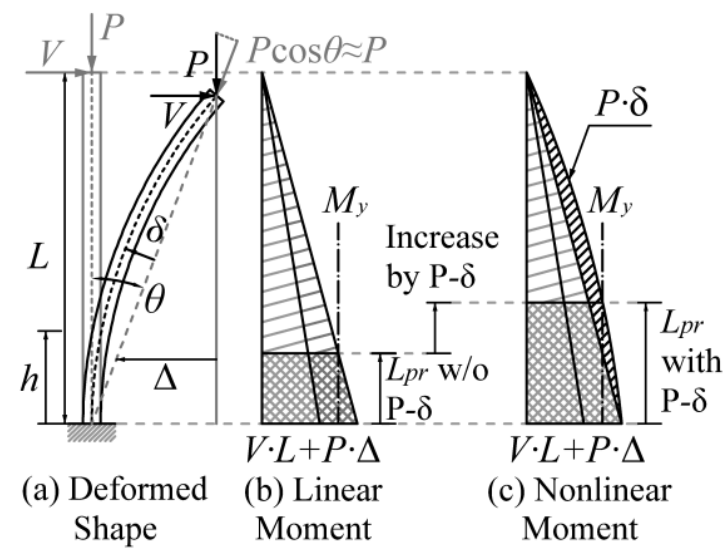

Fig. 1. Effect of nonlinear moment profile and P- $\delta$ on the extent of the plastic region $\left(L_{p r}\right)$

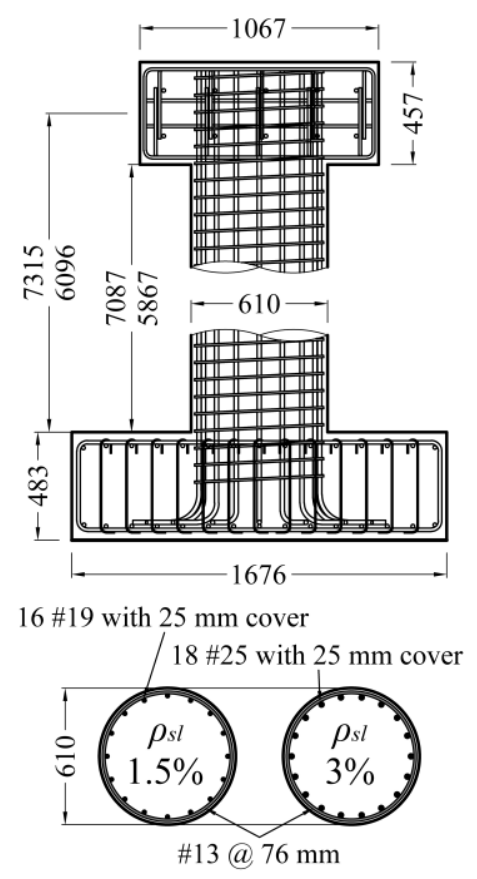

(a) Reinforcement layout

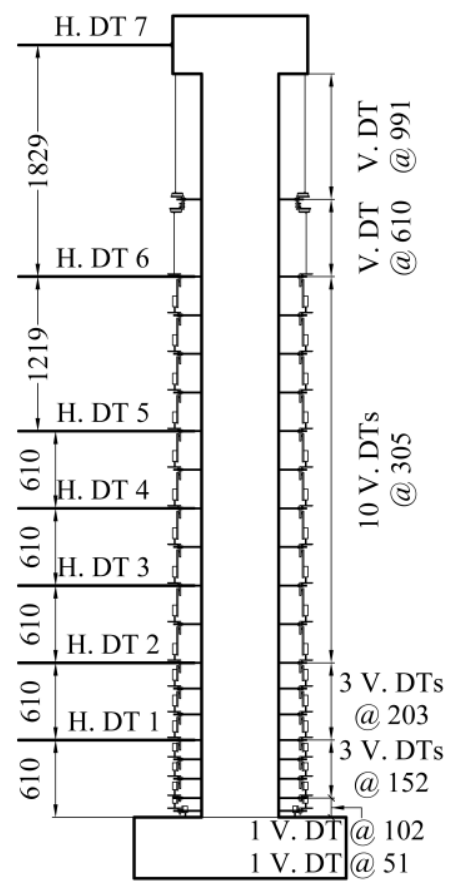

(b) Instruments on M101510

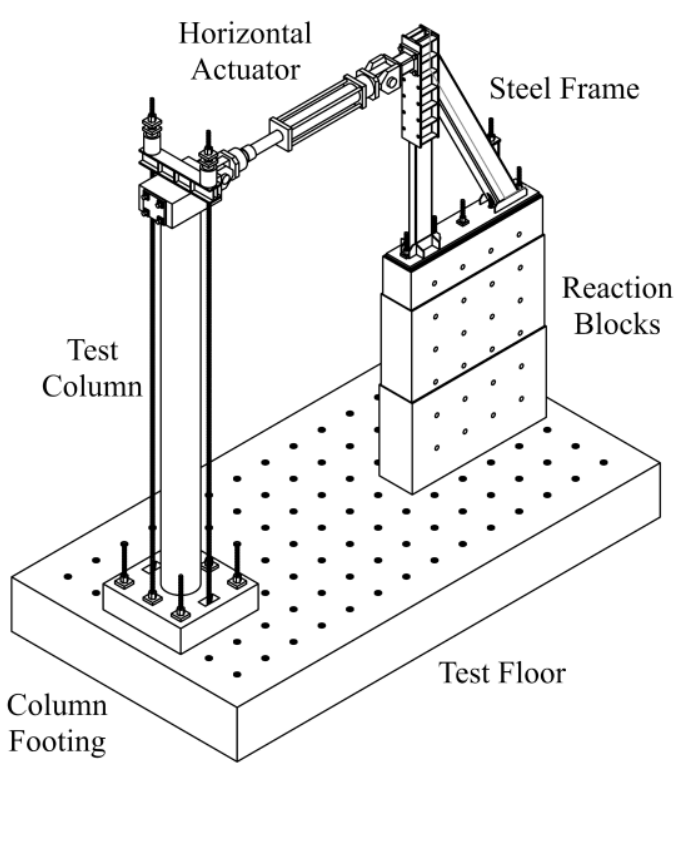

(c) Test setup

Fig. 2. Test setup, reinforcement, and instrumentation layout of test columns

(Note: dimensions in $\mathrm{mm}$ ). 

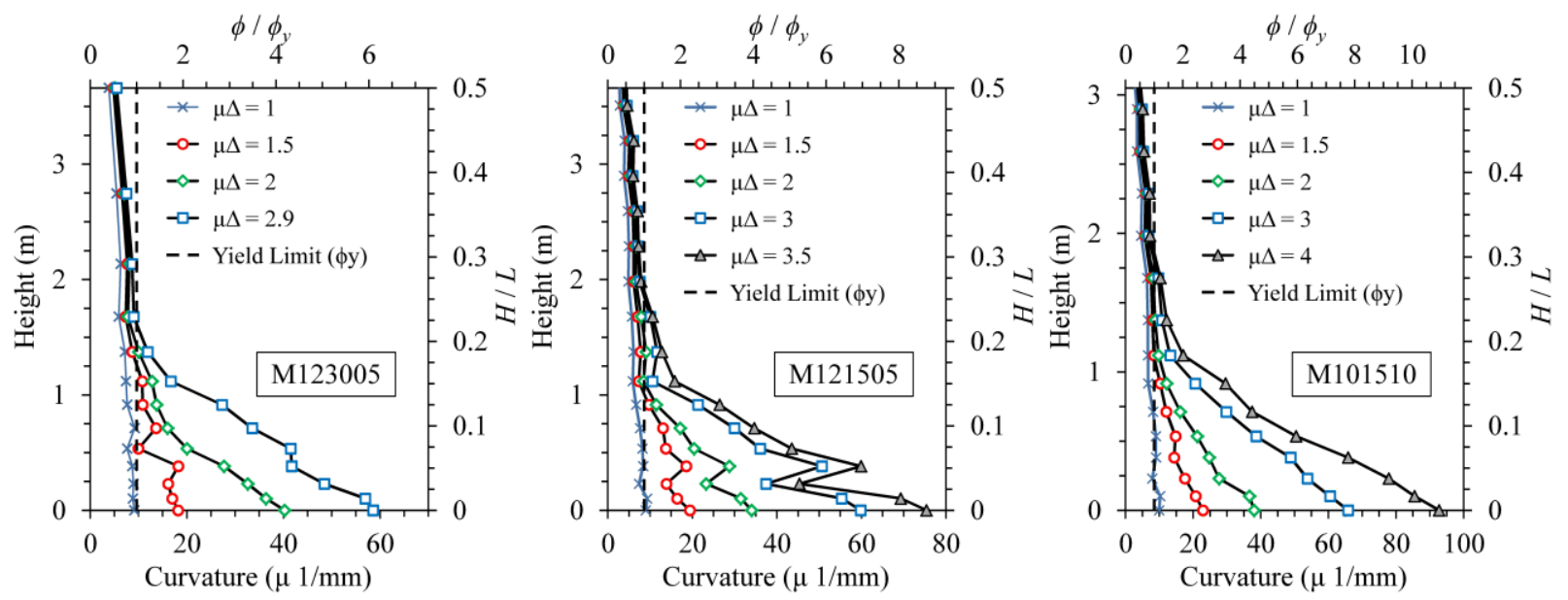

(a) Curvature profiles
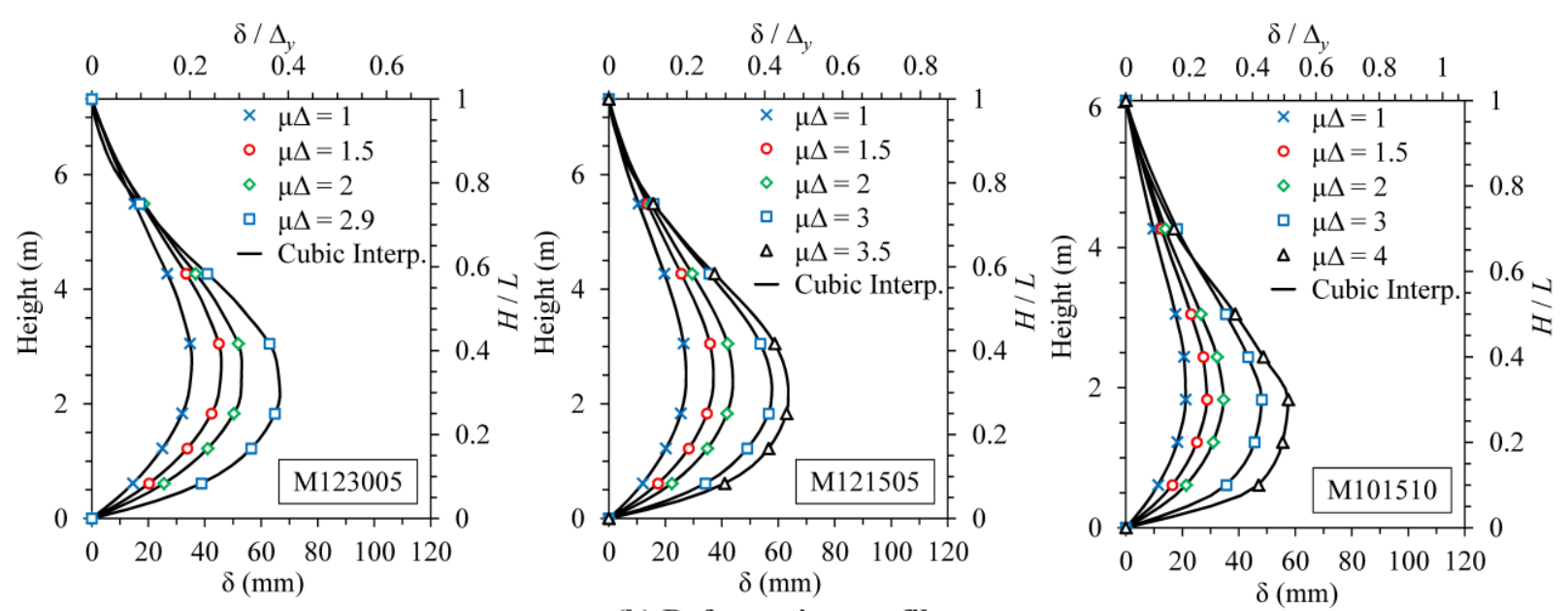

(b) Deformation profiles
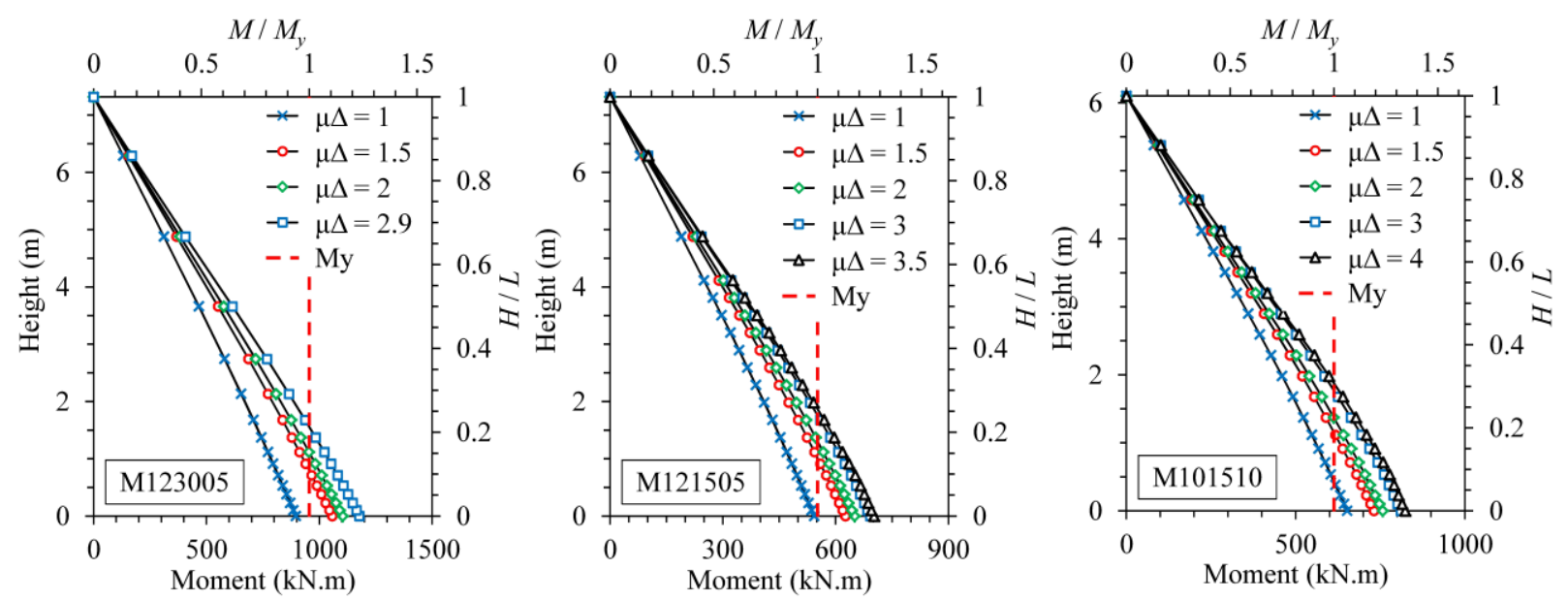

(c) Nonlinear moment profiles

Fig. 3. Experimental profiles of curvature, deformation, and nonlinear moment on test columns 


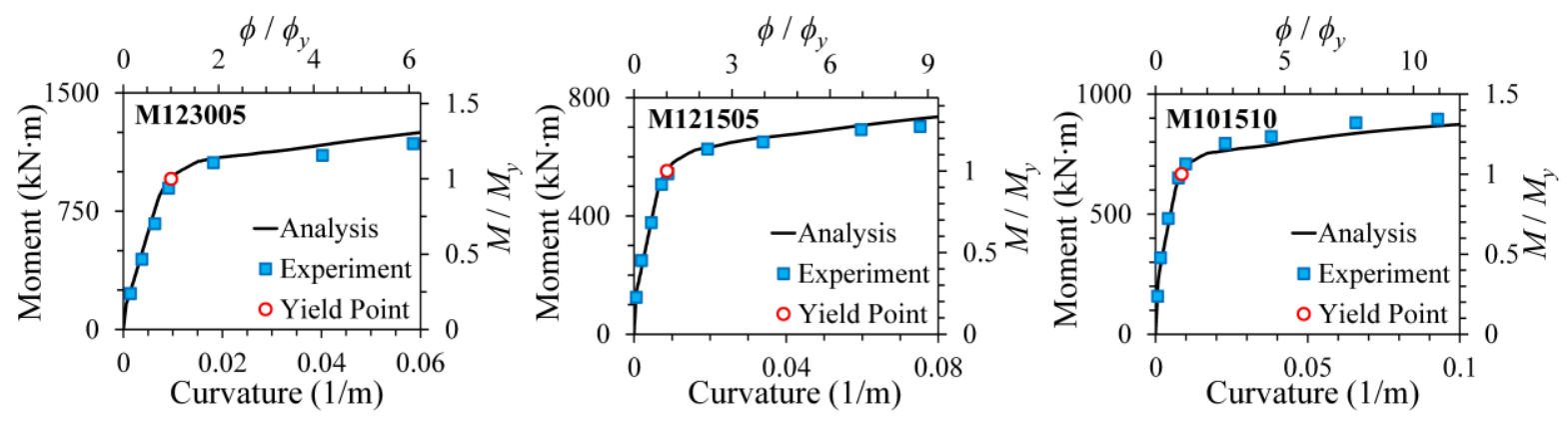

Fig. 4. Experimental and numerical moment-curvature $(M-\phi)$ responses of test columns

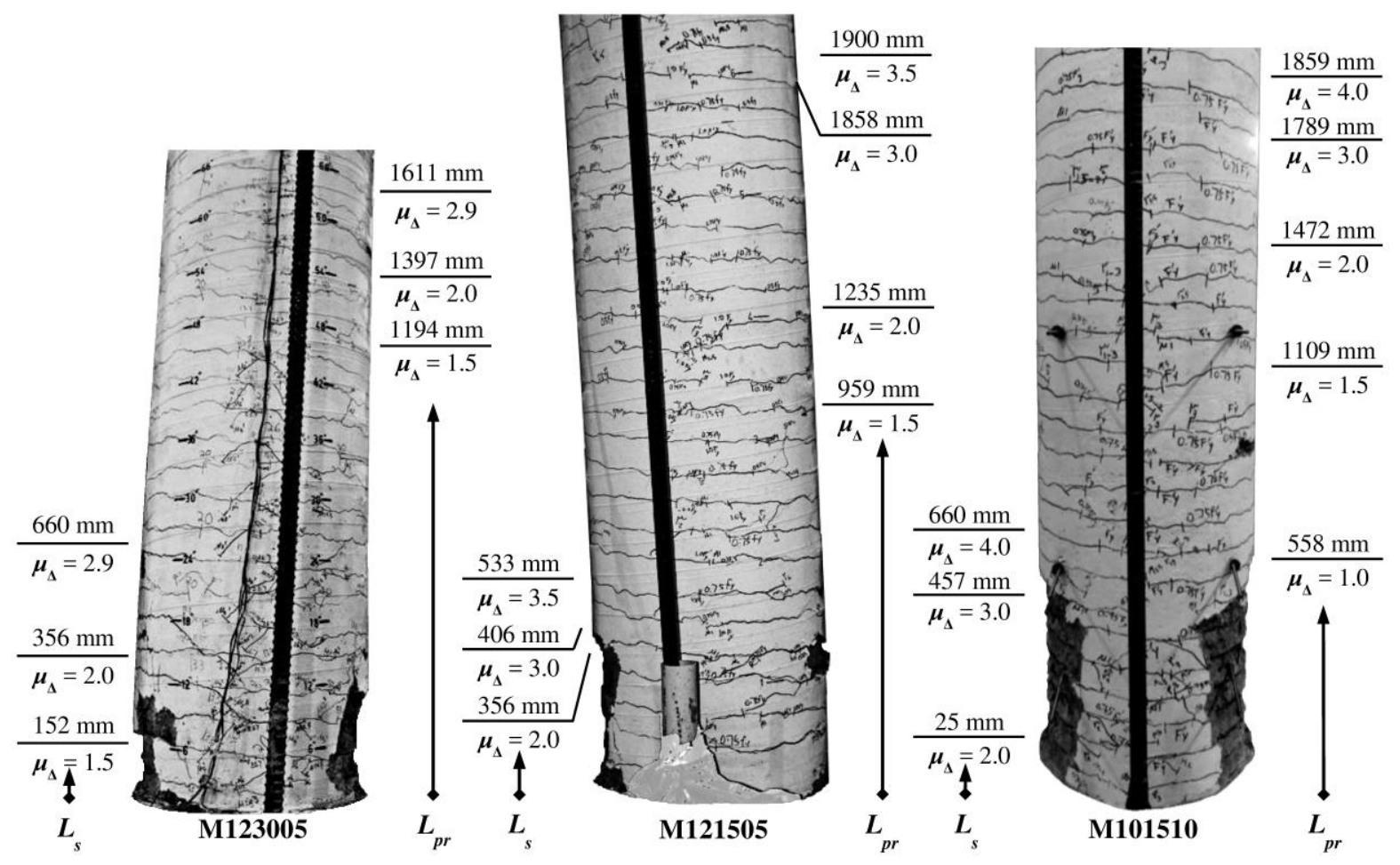

Fig. 5. Extents of the plastic region $\left(L_{p r}\right)$ and spalling zone $\left(L_{s}\right)$ depicted along the test columns at multiple displacement ductility levels 

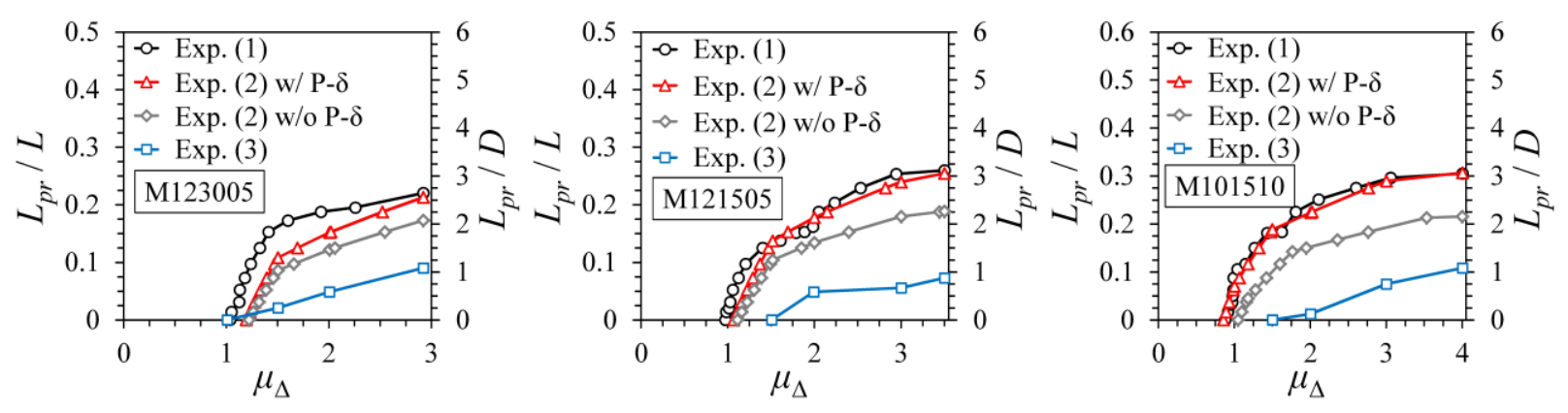

Fig. 6. Extent of the plastic region $\left(L_{p r}\right)$ extracted from the experiments
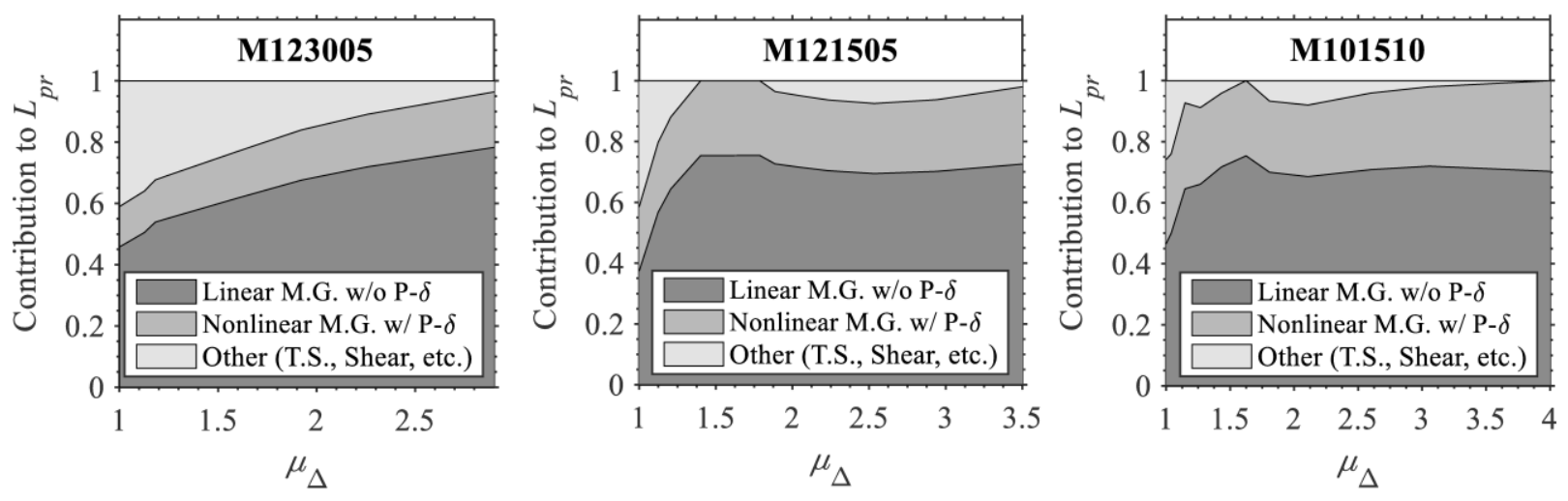

Fig. 7. Major contributors to $L_{p r}$

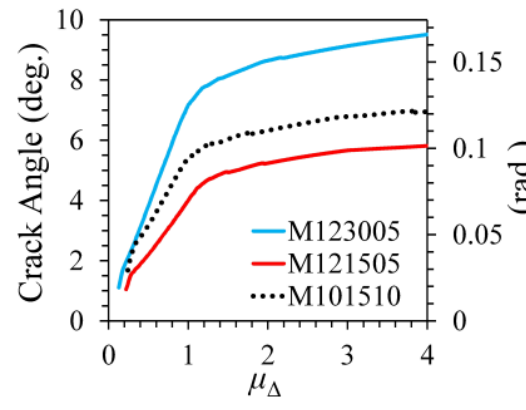

(a) Crack angle

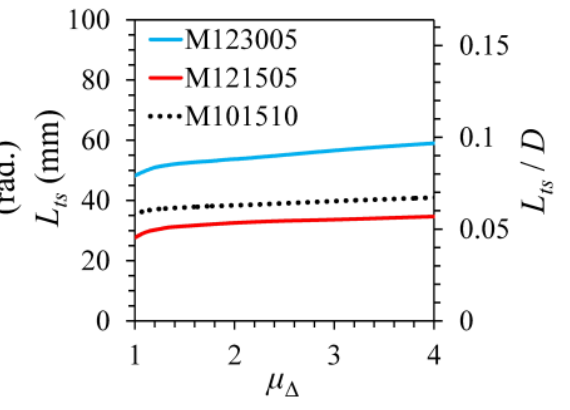

(b) Tension shift effect on $L_{p r}$

Fig. 8. Predicted crack angle and the associated tension shift effect on test columns 


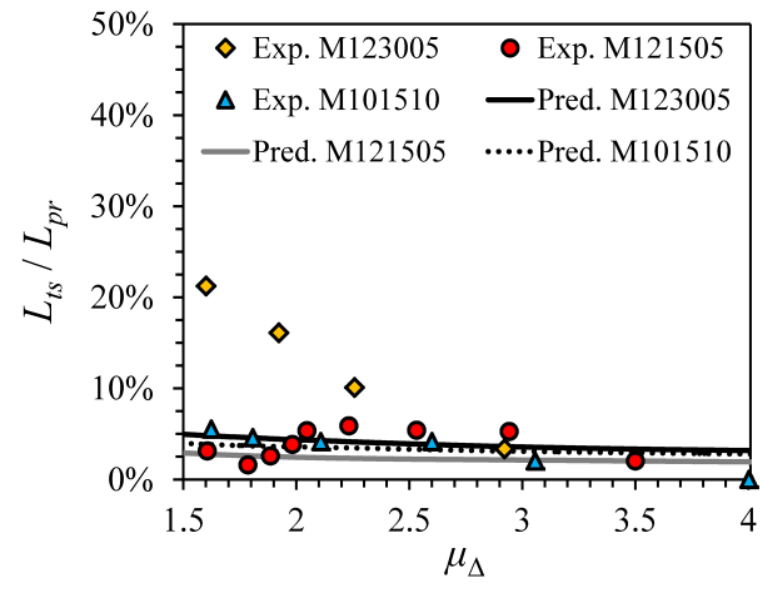

(a) Exp. and pred. contribution of tension shift effect to $L_{p r}$ from the shear crack model [12]

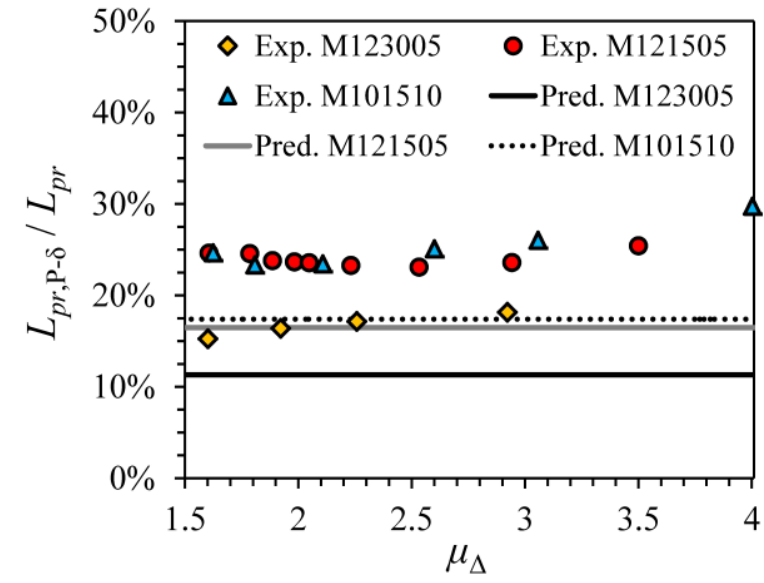

(b) Exp. and pred. contribution of $\mathrm{P}-\delta$ effect to $L_{p r}$ from nonlinear closed-form solution [32]

Fig. 9. Extents of the plastic region due to tension shift effect $\left(L_{t s}\right)$ and P- $\delta$ moment $\left(L_{p r, \mathrm{P}-\delta}\right)$

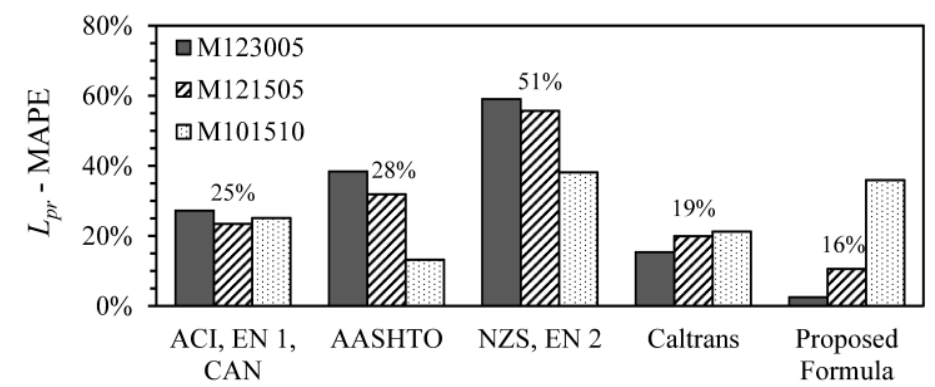

(a) Mean absolute \% error for predicting $L_{p r}$

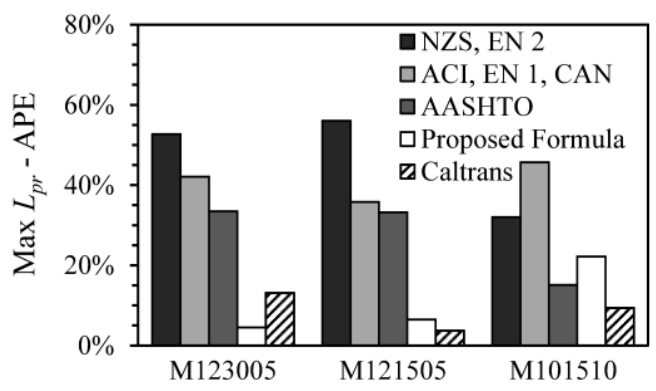

(b) Absolute \% error for predicting maximum $L_{p r}$

Fig. 10. Error associated with the length of the critical plastic region from design codes
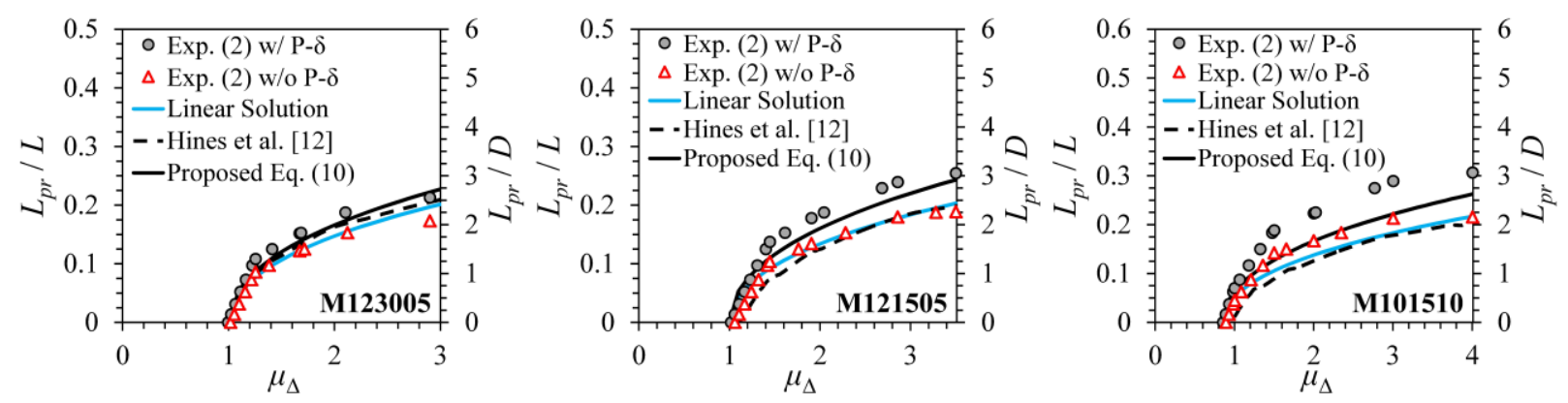

Fig. 11. Comparison of the proposed formula for $L_{p r}$ against the model by Hines et al. [12] 


\section{Tables}

Table 1 Geometrical and material properties of test columns

\begin{tabular}{|c|c|c|c|c|c|c|c|c|c|c|c|c|}
\hline $\begin{array}{c}\text { Test } \\
\text { Column }\end{array}$ & $L / D$ & $\begin{array}{c}L \\
(\mathrm{~m})\end{array}$ & $\begin{array}{c}d_{s l} \\
(\mathrm{~mm})\end{array}$ & $\begin{array}{c}\rho_{s l} \\
(\%)\end{array}$ & $\begin{array}{c}d_{s h} \\
(\mathrm{~mm})\end{array}$ & $\begin{array}{c}\rho_{s h} \\
(\%)\end{array}$ & $\begin{array}{c}P / A_{g} f_{c}^{\prime} \\
(\%)\end{array}$ & $\begin{array}{c}P \\
(\mathrm{kN})\end{array}$ & $\begin{array}{c}f_{c}^{\prime} \\
(\mathrm{MPa})\end{array}$ & $\begin{array}{c}f_{y l} \\
(\mathrm{MPa})\end{array}$ & $\begin{array}{c}f_{u l} \\
(\mathrm{MPa})\end{array}$ & $\varepsilon_{u l}$ \\
\hline $\mathrm{M} 123005$ & 12 & 7.315 & 25.4 & 3.0 & 12.7 & 1.2 & 5.6 & 712 & 46.1 & 486 & 724 & 0.12 \\
\hline $\mathrm{M} 121505$ & 12 & 7.315 & 19.1 & 1.6 & 12.7 & 1.2 & 5.4 & 712 & 42.2 & 455 & 689 & 0.12 \\
\hline $\mathrm{M} 101510$ & 10 & 6.096 & 19.1 & 1.6 & 12.7 & 1.2 & 8.8 & 1334 & 51.8 & 455 & 689 & 0.12 \\
\hline
\end{tabular}

Table 2 Results from moment-curvature analyses

\begin{tabular}{|c|c|c|c|c|c|c|c|c|c|}
\hline $\begin{array}{c}\text { Test } \\
\text { Column }\end{array}$ & $\begin{array}{c}\phi_{y} \\
(\mu 1 / \mathrm{mm})\end{array}$ & $\begin{array}{c}M_{y} \\
(\mathrm{kN} \cdot \mathrm{m})\end{array}$ & $\begin{array}{c}E I_{e l} \\
\left(\mathrm{MN} \cdot \mathrm{m}^{2}\right)\end{array}$ & $\begin{array}{c}\phi_{u} \\
(\mu \mathrm{1} / \mathrm{mm})\end{array}$ & $\begin{array}{c}M_{u} \\
(\mathrm{kN} \cdot \mathrm{m})\end{array}$ & $\begin{array}{c}E I_{i n} \\
\left(\mathrm{MN} \cdot \mathrm{m}^{2}\right)\end{array}$ & $\kappa_{e l}$ & $n$ & $M_{y} / M_{u}$ \\
\hline $\mathrm{M} 123005$ & 9.62 & 958 & 99.6 & 153 & 1395 & 3.79 & 0.618 & 5.13 & 0.69 \\
\hline $\mathrm{M} 121505$ & 8.59 & 552 & 64.3 & 123 & 779 & 1.99 & 0.769 & 5.68 & 0.71 \\
\hline $\mathrm{M} 101510$ & 8.49 & 668 & 78.6 & 127 & 891 & 1.91 & 0.794 & 6.42 & 0.75 \\
\hline
\end{tabular}

Table 3 Comparison between experimental $L_{p r}$ and design guidelines with variable $L_{p r}$

\begin{tabular}{|c|c|c|c|c|c|c|c|c|c|c|c|c|c|c|}
\hline \multirow{3}{*}{$\begin{array}{l}\text { Test } \\
\text { Column }\end{array}$} & \multirow[b]{3}{*}{$\mu_{\Delta}$} & \multirow{3}{*}{$\begin{array}{l}\text { Exp. } \\
L_{p r}(5) \\
(\mathrm{mm})\end{array}$} & \multicolumn{12}{|c|}{ Design Guidelines with Variable Criteria } \\
\hline & & & \multicolumn{4}{|c|}{ AASHTO [10] } & \multicolumn{4}{|c|}{$\begin{array}{c}\text { NZS } 3101[8] \\
\& \text { EN 1998-2 [7] }\end{array}$} & \multicolumn{4}{|c|}{ Caltrans [11] } \\
\hline & & & $\begin{array}{c}L_{p r} \\
\text { w/o } \\
\text { P- } \delta \\
(\mathrm{mm})\end{array}$ & $\begin{array}{l}\mathrm{PE}^{(6)} \\
\%\end{array}$ & $\begin{array}{c}L_{p r} \\
\mathrm{w} / \\
\mathrm{P}-\delta \\
(\mathrm{mm})\end{array}$ & $\begin{array}{c}\mathrm{PE} \\
\%\end{array}$ & $\begin{array}{c}L_{p r} \\
\text { w/o } \\
\mathrm{P}-\delta \\
(\mathrm{mm})\end{array}$ & $\begin{array}{c}\mathrm{PE} \\
\%\end{array}$ & $\begin{array}{c}L_{p r} \\
\mathrm{~W} / \\
\mathrm{P}-\delta \\
(\mathrm{mm})\end{array}$ & $\begin{array}{l}\mathrm{PE} \\
\%\end{array}$ & $\begin{array}{c}L_{p r} \\
\text { w/o } \\
\text { P- } \delta \\
(\mathrm{mm})\end{array}$ & $\begin{array}{l}\mathrm{PE}^{(6)} \\
\%\end{array}$ & $\begin{array}{c}L_{p r} \\
\mathrm{~W} / \\
\mathrm{P}-\delta \\
(\mathrm{mm})\end{array}$ & $\begin{array}{l}\mathrm{PE} \\
\%\end{array}$ \\
\hline \multirow{4}{*}{ 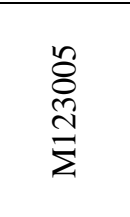 } & $2.5^{(1)}$ & 1495 & 914 & -39 & 914 & -39 & 610 & -59 & 610 & -59 & 1829 & 22 & 1829 & 22 \\
\hline & $3.0^{(2)}$ & $1627^{(9)}$ & 914 & -44 & 1015 & -38 & 610 & -63 & 610 & -63 & 1829 & 12 & 1829 & 12 \\
\hline & $4.1^{(3)}$ & $2105^{(9)}$ & 1218 & -42 & 1583 & -25 & 800 & -62 & 1192 & -43 & 1829 & -13 & 1829 & -13 \\
\hline & $2.9^{(4)}$ & 1611 & 914 & -43 & 975 & -39 & 610 & -62 & 610 & -62 & 1829 & 14 & 1829 & 14 \\
\hline \multirow{4}{*}{$\begin{array}{l}\frac{n}{n} \\
\frac{i}{2} \\
\stackrel{\Sigma}{\Sigma}\end{array}$} & $1.8^{(1)}$ & 1181 & 914 & -23 & 914 & -23 & 610 & -48 & 610 & -48 & 1829 & 55 & 1829 & 55 \\
\hline & $2.3^{(2)}$ & 1530 & 914 & -40 & 1051 & -31 & 610 & -60 & 610 & -60 & 1829 & 19 & 1829 & 19 \\
\hline & $3.1^{(3)}$ & 1862 & 977 & -48 & 1408 & -24 & 610 & -67 & 947 & -49 & 1829 & -2 & 1829 & -2 \\
\hline & $3.5^{(4)}$ & 1900 & 1032 & -46 & 1506 & -21 & 613 & -68 & 1057 & -44 & 1829 & -4 & 1829 & -4 \\
\hline \multirow{4}{*}{$\begin{array}{l}\frac{0}{n} \\
\frac{n}{0} \\
\frac{1}{2}\end{array}$} & $1.4^{(1)}$ & 1028 & 914 & -11 & 1010 & -2 & 610 & -41 & 618 & -40 & 1524 & 48 & 1524 & 48 \\
\hline & $1.7^{(2)}$ & 1234 & 923 & -25 & 1228 & 0 & 610 & -51 & 855 & -31 & 1524 & 24 & 1524 & 24 \\
\hline & $2.3^{(3)}$ & 1587 & 1099 & -31 & 1480 & -7 & 765 & -52 & 1135 & -28 & 1524 & -4 & 1524 & -4 \\
\hline & $4.0^{(4)}$ & 1870 & 1309 & -30 & 1866 & 0 & 990 & -47 & 1553 & -17 & 1524 & -19 & 1866 & 0 \\
\hline$\underset{(7)}{\operatorname{MPE}}$ & - & - & - & -35 & - & -21 & - & -57 & - & -45 & - & 13 & - & 14 \\
\hline$\underset{(8)}{\text { MAPE }}$ & - & - & - & 35 & - & 21 & - & 57 & - & 45 & - & 20 & - & 18 \\
\hline
\end{tabular}

Notes: 
(1) Stability limit according to ACI 318-11 [9].

(2) Stability limit according to Eurocode 8 for buildings [6], and Pettinga and Priestley [37].

(3) Stability limit according to Silva et al. [38].

(4) Maximum displacement ductility level to which the columns were tested.

(5) Experimental $L_{p r}$ from method (1).

(6) Percent error.

(7) Mean percent error.

${ }^{(8)}$ Mean absolute percent error.

${ }^{(9)}$ Extrapolated from the available test data.

Table 4 Comparison of experimental $L_{p r}$ against design guidelines with constant $L_{p r}$

\begin{tabular}{|c|c|c|c|c|c|c|}
\hline \multirow{3}{*}{$\begin{array}{l}\text { Test } \\
\text { Column }\end{array}$} & \multirow{3}{*}{$\mu_{\Delta}$} & \multirow{3}{*}{$\begin{array}{c}\text { Exp. } \\
L_{p r} \\
(\mathrm{~mm})\end{array}$} & \multicolumn{4}{|c|}{$\begin{array}{l}\text { Design Guidelines with } \\
\text { Constant Criteria }\end{array}$} \\
\hline & & & \multicolumn{2}{|c|}{$\begin{array}{c}\text { ACI 318-11 [9] } \\
\& \text { EN 1998-1 [6] }\end{array}$} & \multicolumn{2}{|c|}{$\begin{array}{c}\text { CAN/CSA } \\
\text { A23.3-04 [5] }\end{array}$} \\
\hline & & & $\begin{array}{c}L_{p r} \\
(\mathrm{~mm})\end{array}$ & $\begin{array}{l}\mathrm{PE} \\
\%\end{array}$ & $\begin{array}{c}L_{p r} \\
(\mathrm{~mm})\end{array}$ & $\begin{array}{l}\mathrm{PE} \\
\%\end{array}$ \\
\hline \multirow{4}{*}{ 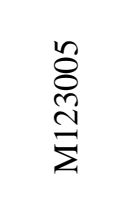 } & 2.5 & 1495 & 1219 & -18 & 1219 & -18 \\
\hline & 3.0 & 1627 & 1219 & -25 & 1219 & -25 \\
\hline & 4.1 & 2105 & 1219 & -42 & 1219 & -42 \\
\hline & 2.9 & 1611 & 1219 & -24 & 1219 & -24 \\
\hline \multirow{4}{*}{$\begin{array}{l}\frac{n}{n} \\
\stackrel{n}{2} \\
\stackrel{\Sigma}{\Sigma}\end{array}$} & 1.8 & 1181 & 1219 & 3 & 1219 & 3 \\
\hline & 2.3 & 1530 & 1219 & -20 & 1219 & -20 \\
\hline & 3.1 & 1862 & 1219 & -35 & 1219 & -35 \\
\hline & 3.5 & 1900 & 1219 & -36 & 1219 & -36 \\
\hline \multirow{4}{*}{$\begin{array}{l}\frac{0}{n} \\
\frac{n}{0} \\
\frac{1}{\Sigma}\end{array}$} & 1.4 & 1028 & 1016 & -1 & 1016 & -1 \\
\hline & 1.7 & 1234 & 1016 & -18 & 1016 & -18 \\
\hline & 2.3 & 1587 & 1016 & -36 & 1016 & -36 \\
\hline & 4.0 & 1870 & 1016 & -46 & 1016 & -46 \\
\hline MPE & - & - & - & -25 & - & -25 \\
\hline MAPE & - & - & - & 25 & - & 25 \\
\hline
\end{tabular}


Table 5 Comparison of experimental $L_{p r}$ against current $L_{p r}$ and $L_{p}$ models

\begin{tabular}{|c|c|c|c|c|c|c|c|c|c|c|c|c|}
\hline \multirow{3}{*}{$\begin{array}{l}\text { Test } \\
\text { Column }\end{array}$} & \multirow{3}{*}{$\mu_{\Delta}$} & \multirow{3}{*}{$\begin{array}{l}\text { Exp. } \\
L_{p r} \\
(\mathrm{~mm})\end{array}$} & \multirow{2}{*}{\multicolumn{2}{|c|}{$\begin{array}{l}\text { Current Models } \\
\text { for } L_{p r} \\
\text { Hines et al. [12] }\end{array}$}} & \multicolumn{6}{|c|}{$\begin{array}{l}\text { Current Models } \\
\text { for } L_{p}^{(1)}\end{array}$} & \multirow{2}{*}{\multicolumn{2}{|c|}{$\begin{array}{l}\text { Proposed } \\
\text { Formula } \\
\text { Eq. (10) }\end{array}$}} \\
\hline & & & & & \multicolumn{2}{|c|}{$\begin{array}{c}\text { Priestley } \\
\text { \& Park [21] }\end{array}$} & \multicolumn{2}{|c|}{$\begin{array}{c}\text { Bae \& } \\
\text { Bayrak [22] }\end{array}$} & \multicolumn{2}{|c|}{$\begin{array}{c}\text { Berry } \\
\text { et al. [23] }\end{array}$} & & \\
\hline & & & $\begin{array}{c}L_{p r} \\
(\mathrm{~mm})\end{array}$ & $\begin{array}{l}\mathrm{PE} \\
\%\end{array}$ & $\begin{array}{c}L_{p r} \\
(\mathrm{~mm})\end{array}$ & $\begin{array}{c}\mathrm{PE} \\
\%\end{array}$ & $\begin{array}{c}L_{p r} \\
(\mathrm{~mm})\end{array}$ & $\begin{array}{l}\text { PE } \\
\%\end{array}$ & $\begin{array}{c}L_{p r} \\
(\mathrm{~mm})\end{array}$ & $\begin{array}{l}\mathrm{PE} \\
\%\end{array}$ & $\begin{array}{r}L_{p r} \\
(\mathrm{~mm})\end{array}$ & $\begin{array}{l}\mathrm{PE} \\
\%\end{array}$ \\
\hline \multirow{4}{*}{ 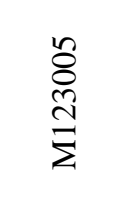 } & 2.5 & 1495 & 1367 & -9 & 1170 & -22 & 362 & -76 & 732 & -51 & 1459 & -2 \\
\hline & 3.0 & 1627 & 1530 & -6 & 1170 & -28 & 362 & -78 & 732 & -55 & 1660 & 2 \\
\hline & 4.1 & 2105 & 1797 & -15 & 1170 & -44 & 362 & -83 & 732 & -65 & 2011 & -4 \\
\hline & 2.9 & 1611 & 1499 & -7 & 1170 & -27 & 362 & -78 & 732 & -55 & 1630 & 1 \\
\hline \multirow{4}{*}{$\frac{n}{n}$} & 1.8 & 1181 & 799 & -32 & 1170 & -1 & 305 & -74 & 732 & -38 & 1056 & -11 \\
\hline & 2.3 & 1530 & 1066 & -30 & 1170 & -24 & 305 & -80 & 732 & -52 & 1322 & -14 \\
\hline & 3.1 & 1862 & 1379 & -26 & 1170 & -37 & 305 & -84 & 732 & -61 & 1644 & -12 \\
\hline & 3.5 & 1900 & 1450 & -24 & 1170 & -38 & 305 & -84 & 732 & -61 & 1777 & -6 \\
\hline \multirow{4}{*}{$\begin{array}{l}\frac{0}{n} \\
\vdots \\
0 \\
\Sigma\end{array}$} & 1.4 & 1028 & 472 & -54 & 975 & -5 & 305 & -70 & 610 & -41 & 570 & -45 \\
\hline & 1.7 & 1234 & 669 & -46 & 975 & -21 & 305 & -75 & 610 & -51 & 744 & -40 \\
\hline & 2.3 & 1587 & 882 & -44 & 975 & -39 & 305 & -81 & 610 & -62 & 995 & -37 \\
\hline & 4.0 & 1870 & 1227 & -34 & 975 & -48 & 305 & -84 & 610 & -67 & 1455 & -22 \\
\hline MPE & - & - & - & -27 & - & -28 & - & -79 & - & -55 & - & -16 \\
\hline MAPE & - & - & - & 27 & - & 28 & - & 79 & - & 55 & - & 16 \\
\hline
\end{tabular}

Note:

(1) $L_{p r}$ was extracted from $L_{p}$ models using Eq. (1). 
Table 6 Summary of the error in predicting $L_{p r}$ in test columns

\begin{tabular}{|c|c|c|c|c|c|}
\hline \multirow{3}{*}{$\begin{array}{c}\text { Test } \\
\text { Column }\end{array}$} & \multicolumn{5}{|c|}{ MAPE (\%) } \\
\hline & \multicolumn{2}{|c|}{$\begin{array}{c}\text { Current } \\
\text { Codes }\end{array}$} & \multicolumn{2}{|c|}{$\begin{array}{l}\text { Current } \\
\text { Models } \\
\end{array}$} & \multirow{2}{*}{$\begin{array}{l}\text { Proposed } \\
\text { Formula } \\
\text { Eq. (10) }\end{array}$} \\
\hline & $\begin{array}{l}\text { W/o } \\
\mathrm{P}-\delta\end{array}$ & $\begin{array}{l}\mathrm{w} / \\
\mathrm{P}-\delta\end{array}$ & $L_{p r}$ & $L_{p}$ & \\
\hline M123005 & $38^{(1)}$ & $35^{(2)}$ & $9^{(3)}$ & $55^{(4)}$ & 3 \\
\hline M121505 & $36^{(1)}$ & $31^{(2)}$ & $28^{(3)}$ & $53^{(4)}$ & 11 \\
\hline M101510 & $31^{(1)}$ & $22^{(2)}$ & $45^{(3)}$ & $54^{(4)}$ & 36 \\
\hline All Cols. & 35 & 29 & 27 & 54 & 16 \\
\hline
\end{tabular}

Notes:

(1) Average error with respect to design guidelines for $L_{p r}$ in references [7,8,10,11].

(2) Average error with respect to design guidelines for $L_{p r}$ in references [6-11].

(3) Average error with respect to models for $L_{p r}$ in reference [12].

(4) Average error with respect to models for $L_{p}$ in references [21-23]. 